\title{
Identification of Burkholderia and Penicillium isolates from kauri (Agathis australis) soils that inhibit the mycelial growth of Phytophthora agathidicida
}

\author{
Alexa-Kate Byers ${ }^{1 *}$, Leo Condron ${ }^{2}$, Maureen O'Callaghan ${ }^{3}$, Nick Waipara ${ }^{4}$ and Amanda Black ${ }^{1}$ \\ ${ }^{1}$ Bioprotection Aotearoa, Lincoln University, P.O. Box 85084, Lincoln 7647, New Zealand \\ ${ }^{2}$ Faculty of Agriculture and Life Sciences, Lincoln University, P.O. Box 85084, Lincoln 7647, New Zealand \\ ${ }^{3}$ AgResearch Ltd, 1365 Springs Road, Lincoln 7674, New Zealand \\ ${ }^{4}$ The New Zealand Institute of Plant and Food Research Ltd, Private Bag 92169, Auckland 1142, New Zealand \\ *Corresponding author: alexabyers@outlook.com
}

(Original submission received 26 March 2021; accepted in revised form 22 August 2021)

\begin{abstract}
Phytophthora agathidicida is a highly virulent pathogen of kauri (Agathis australis) and the causal agent of dieback disease in New Zealand's kauri forests. This study aimed to identify microbial isolates isolated from kauri forest soils that inhibited the growth of $P$. agathidicida. Three different forms of in vitro bioassays were used to assess the inhibition of each isolate on the mycelial growth of $P$. agathidicida. Furthermore, head space (HS) solid-phase micro-extraction coupled with gas chromatography-mass spectrometry (SPME-GCMS) was performed to identify if the microbial isolates emitted volatile organic compounds (VOCs), which may be contributing to inhibition. This research identified several bacterial isolates belonging to the genus Burkholderia that inhibited the mycelial growth of P. agathidicida. Furthermore, several VoCs produced by these isolates were putatively identified, which may be responsible for the inhibition observed in the bioassays. Several isolates of Penicillium were identified that inhibit Phytophthora agathidicida, with the culture filtrate of one isolate being found to strongly inhibit $P$. agathidicida mycelial growth. These isolates of Burkholderia and Penicillium appear to exhibit multiple modes of antagonism against $P$. agathidicida, including microbial competition and the production of diffusible and volatile anti-microbial compounds. Although further research is needed to better define their mechanisms of inhibition, these findings have identified candidate microbial antagonists of $P$. agathidicida.
\end{abstract}

Keywords Phytophthora agathidicida; Burkholderia; Penicillium; headspace solid-phase micro-extraction gas chromatography-mass spectrometry (HS SPME-GC-MS) analysis; volatile organic compounds; in vitro bioassay

\section{INTRODUCTION}

The spread of kauri dieback, caused by the pathogen Phytophthora agathidicida, currently threatens the longterm health of New Zealand's kauri (Agathis australis) forests (Beever et al. 2009). Kauri dieback was first recognised to be afflicting kauri on Great Barrier Island (Hauraki Gulf, Auckland) in the 1970s, and is now widespread across most mainland kauri forests (Gadgil 1974; Waipara et al. 2013). Kauri dieback is a root and collar rot disease that is spread through the movement of soil and root pieces infested with P. agathidicida (Bellgard et al. 2016). Current management strategies primarily focus on disease containment by preventing further spread of P. agathidicida infested soils into new forested areas (Bradshaw et al. 2020). Several research efforts have been made to manage the disease which include phosphite injections directly into trees (Horner \& Hough 2013), oospore deactivation (Dick \& Kimberley 2013), screening kauri for genetic resistance (Herewini et al. 2018) and mātauranga Māori guided discovery of native plant bio- actives with anti-Phytophthora properties (Lawrence et al. 2019).

Despite these scientific studies, there has been limited research on how the soil microbiota may suppress kauri dieback by antagonising $P$. agathidicida. Several plant diseases caused by Phytophthora pathogens have, in part, been managed using chemical control, such as potato (Solanum tuberosum) late blight caused by $P$. infestans (Majeed et al. 2017) and pepper (Capsicum annuum) blight caused by P. capsici (Kim et al. 2010). However, there are concerns over the widespread use of chemical control due to the associated environmental impacts and the development of fungicide resistance (O'Brien 2017). Disease management strategies that integrate the use of microbial agents to antagonise pathogens and prevent plant infection are considered to be a more sustainable, less environmentally impactful alternative (Bhusal \& Mmbaga 2020). For the management of soil-borne plant pathogens, it is preferential to target the discovery of microbial antagonists to the host 
associated soil microbiota. Members of the resident soil microbiota are more likely to establish, proliferate and elicit the functional traits required to suppress plant disease when applied in field settings (Raaijmakers et al. 2009; Zohara et al. 2016).

Previous research by Byers et al. (2020) identified significant differences in the composition of fungal and bacterial communities associated with asymptomatic and symptomatic kauri trees across Waipoua Forest (Northland Region, New Zealand). Several of the microbial taxa found in significantly higher relative abundance in asymptomatic kauri soils have been previously reported to inhibit various other Phytophthora pathogens. These include genera such as Penicillium (Fang \& Tsao, 1995; Ma et al., 2008), Trichoderma (Ahmed et al. 2000; Widmer 2014; Bae et al. 2016), and Pseudomonas (Tran et al. 2007; Zohara et al. 2016; Caulier et al. 2018). Although Byers et al. (2020) identified microbial taxa associated with potentially disease suppressive soils (i.e. asymptomatic host states), it did not assess whether these taxa exhibit an antagonistic interaction against Phytophthora agathidicida. Therefore, additional research is needed to isolate and identify members of the kauri soil microbiota that can be demonstrated to inhibit the growth of $P$. agathidicida ${ }^{1}$.

In this study, we aimed to isolate microorganisms from soils associated with asymptomatic kauri to identify if any suppressed the mycelial growth of $P$. agathidicida. Three different bioassay types were used to assess each microbial isolate: dual culture bioassays, culture filtrate bioassays, and split plate bioassays. Dual culture bioassays were selected as the primary form of bioassay because they were a fast and easily reproducible method to screen many microbial isolates against $P$. agathidicida (Kunova et al. 2016; Zohara et al. 2016). To provide more insight into the mechanisms driving mycelial inhibition, culture filtrate bioassays were used to assess whether diffusible compounds produced by the microbial isolates were contributing to inhibition (Ma et al. 2008; Zohara et al. 2016). In addition, split plate bioassays were used as a method to assess whether the microbial isolates were producing volatile organic compounds (VOCs) that may be inhibiting $P$. agathidicida (Syed-Ab-Rahman et al. 2019).

Volatile organic compounds (VOCs) are secondary metabolites released by soil microorganisms that are known to exhibit anti-microbial properties against a wide range of plant pathogens (de Boer et al. 2019). Due to their low molecular mass, high vapour pressure and low boiling point (Insam \& Seewald 2010; Piechulla \& Degenhardt 2014), microbial VOCs can readily evaporate and diffuse through the soil to interact with other soil microorganisms (Effmert et al. 2012; Bitas et al. 2013; Schmidt et al. 2015). VOCs have been demonstrated to inhibit several Phytophthora pathogens including $P$. infestans (Hunziker et al. 2015; Kumar et al. 2018; Elsherbiny et al. 2020), P. capsici (Syed-Ab-Rahman et al. 2019), and P. cinnamomi (Méndez-Bravo et al. 2018). This study used solid-phase micro-extraction (SPME) coupled with gas chromatography-mass spectrometry (GC-MS) to

\footnotetext{
$\overline{1}$ The genus name Phytophthora has been abbreviated to $P$. in instances where it would not be confused with another genus. All other genera starting with the letter $\mathrm{P}$ are spelt out in full throughout the text.
}

extract and identify VOCs from the headspace (HS) of the isolates found to inhibit $P$. agathidicida, so that the potential mechanisms driving inhibition could begin to be explored.

\section{MATERIALS AND METHODS \\ Isolation of microorganisms from kauri soil}

The microbial isolates screened against $P$ agathidicida during this study were isolated from organic layer soils collected from asymptomatic kauri trees across Waipoua Forest (Northland Region, New Zealand). Soil samples were collected during previous soil sampling as outlined by Byers et al. (2020). Following sampling, soils were temporarily stored at $4^{\circ} \mathrm{C}$ in darkness prior to use in this study. One of the wider aims of this kauri dieback project was to understand the microbiome associated with soils associated with asymptomatic kauri trees, i.e. those near diseased trees in infected kauri stands (Byers et al 2020). Therefore, only kauri soil samples that tested negative for the presence of $P$. agathidicida when screened using a soil baiting bioassay and real-time PCR assay (Than et al. 2013; McDougal et al. 2014) were used in this study.

Microbial isolates were isolated from kauri soils using soil serial dilutions and selective agar plating (Zohara et al.2016). Eight soil samples were randomly selected from the store of uninfected kauri soil outlined above. Per sample, triplicate $1 \mathrm{~g}$ subsamples were suspended in $100 \mathrm{~mL}$ of autoclaved double-distilled (dd) $\mathrm{H}_{2} \mathrm{O}$ and shaken at $140 \mathrm{rpm}$ on an orbital shaker (Ratek Instruments Pty Ltd., Australia) for 4 hours at room temperature before being left to settle for 1 hour. Once settled, $1 \mathrm{~mL}$ of each soil suspension was diluted at a $1: 10$ concentration with autoclaved $\mathrm{ddH}_{2} \mathrm{O}$. Following this, $1 \mathrm{~mL}$ of each serial dilution was plated onto a bacterial selective and a fungal selective agar plate and spread evenly across the surface of the plate using a cell spreader. Recipes for the bacterial selective and fungal selective agar plates are listed in the Supplementary Methods.

Selective agar plates were incubated for up to 4 days in darkness at $21.5^{\circ} \mathrm{C}$, which is the optimum growth temperature of $P$. agathidicida (Weir et al. 2015). This incubation temperature was selected to cultivate microbial isolates compatible for growth in bioassay screenings with $P$. agathidicida. Plates were inspected every 24 hours, with emerging fungal and bacterial colonies immediately subcultured onto potato dextrose agar (PDA) (Oxoid Ltd., UK) and nutrient agar (NA) (Oxoid Ltd., UK), respectively. By the end of this selective isolation process, 164 bacterial isolates and 170 fungal isolates were isolated from and used for prescreening assays. Microbial isolates were temporarily stored on half strength PDA or NA plates in darkness at $4^{\circ} \mathrm{C}$ before being screened.

\section{P. agathidicida source material}

The $P$. agathidicida strain NZFS3770 was used to conduct experiments throughout the duration of this study. This isolate was cultured on $10 \%$ carrot agar, ampicillin, nystatin, rifampicin, pimaricin and hymexazol (CRNH) selective medium (Herewini et al. 2018) to preserve pure cultures and maintained on $20 \%$ clarified V8 agar in darkness at $21.5^{\circ} \mathrm{C}$ (Lawrence et al. 2017). 


\section{Pre-screening of microbial isolates}

Due to the high number of isolates that required screening, pre-screening rounds were conducted before beginning more detailed bioassays. For pre-screenings, dual culture bioassays were prepared in triplicate for each microbial isolate. These dual culture bioassays are fully described in the following Section. Only isolates that reduced the mycelial growth (mm) of P. agathidicida when compared to the control were retained for further bioassay analysis using more dual culture bioassays, culture filtrate bioassays and split plate bioassays.

\section{Dual culture bioassays}

Microbial isolates that passed pre-screening were screened against $P$. agathidicida again using dual culture bioassays at a higher replication number. To prepare bacterial isolates for the dual culture bioassays, each isolate was streaked out onto an NA plate and incubated for in darkness at $21.5^{\circ} \mathrm{C}$ for 24 hours. Single colonies were inoculated into $15 \mathrm{~mL}$ of sterile tryptone soya broth (TSB) (Oxoid Ltd., UK) using a $1-\mu \mathrm{L}$ inoculation loop. Broth cultures were shaken at $100 \mathrm{rpm}$ on an orbital shaker (Ratek Instruments Pty Ltd., Australia) in darkness at $21.5^{\circ} \mathrm{C}$ for 48 hours. After incubation, broth cultures were centrifuged (4000 rpm for 20 minutes) and the supernatant was discarded. Bacterial pellets were suspended in $500 \mu \mathrm{L}$ of autoclaved $\mathrm{dd}_{2} \mathrm{O}$. To prepare the fungal isolates and P. agathidicida for dual culture bioassays, a 5-mm diameter agar plug of each isolate was sub-cultured onto a fresh PDA plate and incubated in darkness at $21.5^{\circ} \mathrm{C}$ for 5 days.

To set up the dual culture bioassays, a 5-mm diameter agar plug of $P$. agathidicida was taken from the leading mycelial edge and placed into the centre of a PDA plate. For each fungal isolate, two 2.5-mm diameter agar plugs were positioned $2 \mathrm{~cm}$ away from the P. agathidicida agar plug and on opposite sides of the PDA plate. For bacterial isolates, PDA plates were inoculated with two $50 \mu \mathrm{L}$ doses of liquid culture in the same positions as described for fungal isolates. Control plates were prepared by inoculating PDA plates that contained a 5-mm diameter agar plug of $P$. agathidicida with either two $2.5-\mathrm{mm}^{2}$ blank PDA agar plugs or two $50-\mu \mathrm{L}$ doses of autoclaved $\mathrm{ddH}_{2} \mathrm{O}$. A graphical description of this experimental set up can be seen in Fig. S1 (Supplementary Materials).

\section{Culture filtrate bioassays}

Broth cultures of each bacterial isolate were prepared as described in the previous section. Following incubation at $21.5^{\circ} \mathrm{C}$ for 48 hours, bacterial cultures were centrifuged (4000 rpm for 40 minutes) and the resulting supernatant was double filtered using cellulose acetate ReliaPrep ${ }^{\mathrm{TM}}$ $0.2 \mu \mathrm{M}$ syringe filters (Ahlstrom-Munksjö, Finland) to a obtain a cell-free filtrate. Methods for the fungal isolates followed those described above for bacterial isolates. However, fungal broth cultures were prepared by inoculating $25 \mathrm{~mL}$ of sterile malt extract broth (MEB) (Oxoid Ltd., UK) with three 5 -mm diameter agar plugs of each fungal isolate which were then incubated in darkness at $25^{\circ} \mathrm{C}$ for 5 days.

To set up the culture filtrate bioassays, one 5-mm diameter agar plug of $P$. agathidicida was sub-cultured onto a PDA plate. Following this, $500 \mu \mathrm{L}$ of either bacterial or fungal cell free filtrate was pipetted directly onto the $P$. agathidicida agar plug (Vinale et al. 2006; Ma et al. 2008; Zohara et al. 2016). Control plates consisted of one 5-mm diameter agar plug of $P$ agathidicida which was inoculated with either $500 \mu \mathrm{L}$ of sterile TSB or MEB.

\section{Split plate bioassays}

Methods for split-plate bioassays were modified based methods outlined by Syed-Ab-Rahman et al. (2019). Splitplate Petri dishes (Thermo Fisher Scientific, New Zealand) which had a $0.5-\mathrm{mm}$ wide strip of agar cut out to further separate each microbial isolate from $P$. agathidicida were used to set up the bioassays. Bacterial broth cultures and fungal agar cultures were prepared as described in the section on dual culture bioassays. Following preparation, either $100 \mu \mathrm{L}$ of bacteria or a 5-mm diameter agar plug of fungi was inoculated onto one side of a split PDA plate. The opposite side of the split PDA plate was then inoculated with a 5-mm diameter agar plug of $P$. agathidicida. Example images of bacterial split plate bioassays can be seen in Fig. S2 (Supplementary Materials).

\section{Calculation of $P$. agathidicida inhibition}

Following preparation, all bioassays were incubated in darkness at $21.5^{\circ} \mathrm{C}$ for 7 days before $P$. agathidicida was measured for its mycelial growth ( $\mathrm{mm}$ ). Each of the three different bioassay types were repeated for three rounds and for each of the three rounds, five replicates were performed per microbial isolate. Following incubation, the mycelial inhibition (MI) value (\%) of each bioassay was calculated using the formula: ' $((C-A) / C) \times 100)$ '. Where, $C$ is the growth (mm) of $P$. agathidicida on control plates and $A$ is the growth (mm) of $P$. agathidicida on plates inoculated with a microbial isolate. Significant differences $(p$-value $<0.05)$ in MI values (\%) between experimental and control bioassays were determined using Students T-tests ( $p$-value $<0.05)$.

\section{Profiling of VOCs using HS SPME-GC-MS}

Headspace solid-phase micro-extraction coupled with gas chromatography-mass spectrometry (HS SPME-GC-MS) was performed to profile the VOCs released by the microbial isolates. To prepare for analysis, fungal isolates were subcultured onto a PDA plate and incubated at $21.5^{\circ} \mathrm{C}$ in darkness for 7 days. Following this, four 5-mm diameter agar plugs were transferred into a $20 \mathrm{~mL}$ amber glass headspace vial (Supelco Analytical, Sigma Aldrich) and incubated at $21.5^{\circ} \mathrm{C}$ for 24 hours. Liquid cultures of bacterial isolates were prepared as described in the section on dual culture bioassays. Following preparation, $100 \mu \mathrm{L}$ of bacteria was inoculated into a headspace vial containing $3 \mathrm{~mL}$ of NA and incubated at $21.5^{\circ} \mathrm{C}$ for 24 hours. To prepare $P$. agathidicida only control vials, an agar plug of $P$. agathidicida was freshly sub-cultured onto PDA and incubated in darkness at $21.5^{\circ} \mathrm{C}$ for 5 days. Following incubation, four $5-\mathrm{mm}$ diameter agar plugs were transferred into a headspace vial and incubated at $21.5^{\circ} \mathrm{C}$ for 24 hours. As further controls, headspace vials containing either four 5-mm diameter blank PDA plugs or $3 \mathrm{~mL}$ of NA inoculated with autoclaved $\mathrm{ddH}_{2} \mathrm{O}$ were prepared and incubated at the same conditions 
as the sample vials. Three replicate headspace vials were set up for all experimental and control samples analysed. During incubation, headspace vials were plugged with a sterile cotton ball to maintain aerobic conditions. Following incubation, cotton ball plugs were discarded, and headspace vials were sealed with an 18-mm thread magnetic screw cap that contained a $1.5 \mathrm{~mm}$ thick blue PTFE/silicone septum (Supelco Analytical, Sigma Aldrich).

Methods for the HS SPME-GC-MS analysis followed those outlined by Stoppacher et al. (2010) and Nieto-Jacobo et al. (2017). A Shimadzu QP2010 gas chromatograph-mass spectrometer (Shimadzu Corporation, Japan) fitted with a CTC-CombiPAL XYZ auto sampler and a Restek Rxi-5 ms fused silica capillary column (HP5-MS $30 \mathrm{~m} \times 0.25 \mathrm{~mm}$ $\times 0.25 \mu \mathrm{m}$, Bellefonte, PA, USA) was used to perform the analysis. VOCs were extracted from the sample headspace vials for 30 minutes without agitation using an SPME fibre that had a $65 \mu \mathrm{M}$ polydimethylsiloxane/divinylbenzene (PDMS/DVB) coating. After injection, volatiles bound to the fibre were desorbed for 2 minutes in a split/split less injector at $250^{\circ} \mathrm{C}$. The oven temperature programme was held at $40^{\circ} \mathrm{C}$ for 2 minutes; raised $10^{\circ} \mathrm{C}$ per minute to $200^{\circ} \mathrm{C}$; further raised $25^{\circ} \mathrm{C}$ per minute to $260^{\circ} \mathrm{C}$ and then held at $260^{\circ} \mathrm{C}$ for 5 minutes. Helium was used as carrier gas at a constant flow rate of $1 \mathrm{~mL}$ per minute.

The acquisition and processing software GCMS solution version 4.45 (Shimadzu Corporation, Japan) was used to putatively identify the best match for each detected compound. This software used the NIST 2011 and Wiley 10 mass spectral libraries to identify compounds in conjunction with their reported linear retention index (LRI) information. An alkane standard solution $\mathrm{C}_{8}-\mathrm{C}_{20}$ (Sigma-Aldrich, Australia) was run to calculate LRI values for each identified compound. The reported LRI values for each compound were compared to previously reported literature LRI values, which were obtained from ChemSpider (http://www.chemspider. com/), NIST Chemistry WebBook (https://webbook.nist. gov/chemistry/), PubChem (https://pubchem.ncbi.nlm. nih.gov/), and Pherobase (https://www.pherobase.com/) (Table S1, Supplementary Materials).

Only compounds with an LRI value within $\pm 2 \%$ of their literature LRI value were accepted as a putatively identified substance. Furthermore, only compounds with a compound match rate of over $85 \%$ and that were present in at least two of the three biological replicates were retained as accepted compounds (Table S2, Supplementary Materials). The vast majority ( $>85 \%$ ) of the compounds detected were contaminants (siloxanes) which are commonly emitted from the sample vials. Contaminants were characterised by removing all compounds detected in control vials from the vials containing samples prior to analysis. Compounds detected in the headspace of control vials were predominantly contaminants (siloxanes) from the vials. These materials represented $>85 \%$ of all compounds detected in the samples and were subtracted from the list of compounds detected in the headspace of sample vials. Following putative identification, individual VOCs were assigned into chemical classes using mVOC 2.0 (Lemfack et al. 2018) and ClassyFire (Djoumbou Feunang et al. 2016).

\section{Genomic identification of microbial isolates}

Microbial isolates that passed pre-screening were subjected to preliminary taxonomic identification. Microbial DNA was extracted from liquid bacterial cultures and fungal agar plugs using a DNeasy UltraClean Microbial Kit (Qiagen, Germany) according to manufacturer's instructions. Methods for PCR amplification of the 16S rRNA gene region and ITS2 gene region are outlined in the Supplementary Methods. PCR products were cleaned using a Magnetic Bead PCR Cleanup Kit (Geneaid Biotech Ltd., Taiwan) and sequenced at the Lincoln University DNA Sequencing facility (Lincoln, New Zealand). Following sequencing, low quality ends were trimmed and forward and reverse reads were aligned using UniPro UGENE (version 36.0) software (Okonechnikov et al. 2012). Microbial isolates were identified to genus level based on the identity of their closest match from the NCBI BLAST rRNA and ITS database (GenBank). Bacterial 16S rRNA and fungal ITS2 gene regions were deposited in the NCBI database under the GenBank accession numbers shown in Table 1. To compare the relatedness of the 16S rRNA/ ITS2 gene region sequences, multiple sequence alignments were performed by progressive pairwise alignment using Geneious Prime 2020.2.4 (https://www.geneious.com). Parameters for Geneious alignment were set to default. To build phylogenetic trees, the Neighbour Joining tree build method was selected using Tamura-Nei genetic distance models and bootstrap resampling.

\section{RESULTS}

\section{Genomic identification of isolates}

From the 11 bacterial isolates identified to significantly inhibit P. agathidicida mycelial growth in dual culture bioassays, nine were identified as belonging to the genus Burkholderia, one was identified as a Paraburkholderia, and one as Pseudomonas. All nine fungal isolates that significantly inhibited Phytophthora agathidicida in dual culture bioassays were identified to belong to the genus Penicillium (Table 1). Figures S3 and S4 (Supplementary Materials) show the phylogenetic relationships between the bacterial and fungal isolates displayed in Table 1.

\section{In vitro bioassays}

Dual culture bioassays

When tested using dual culture bioassays, all fungal and bacterial isolates that passed pre-screening significantly reduced $P$. agathidicida mycelial growth compared with $P$. agathidicida only control plates ( $p$-value $<0.001$, Fig. 1 and Fig. 2).

Fungal isolates with the highest mean mycelial inhibition (MI, \%) were Penicillium ks20_f18 (58.28 \pm 1.55$)$, Penicillium ks20_f30 (57.27 \pm 1.20$)$, and Penicillium ks20_f52 (55.27 \pm 1.26). Bacterial isolates with the highest mean MI values (\%) were Burkholderia ks20_b71 (60.88 \pm 3.22), Burkholderia ks20_b12 (59.91 \pm 1.84), and Burkholderia ks20_b69 (59.78 \pm 1.37$)$. Images of fungal and bacterial dual culture bioassays are shown in Fig. S5 and Fig. S6, Supplementary Materials. The results of the bioassays and the statistical tests are provided in more detail in Tables S3 and S4, Supplementary Materials. Several isolates of Penicillium 
Table 1 Identification of bacterial and fungal isolates that significantly inhibited Phytophthora agathidicida in dual culture bioassays. The taxonomic assignment of each bacterial and fungal isolate was performed to genus level based on the identity of their closest match when their 16S rRNA/ITS2 gene region sequences were searched in the NCBI BLAST database.

\begin{tabular}{|c|c|c|c|c|}
\hline Identified isolate & Accession number & Closest match & Expect value & $\%$ match \\
\hline Burkholderia ks20_b4 & MW041148 & B. catarinensis (NR_153664.1) & 0.0 & 99.15 \\
\hline Burkholderia ks20_b8 & MW040830 & B. catarinensis (NR_153664.1) & 0.0 & 98.44 \\
\hline $\begin{array}{l}\text { Paraburkholderia } \\
\text { ks20_b72 }\end{array}$ & MW040841 & $\begin{array}{l}\text { Paraburkholderia metalliresistens } \\
\text { (NR_118054) }\end{array}$ & 0.0 & 97.51 \\
\hline Burkholderia ks20_b9 & MW040831 & B. catarinensis (NR_153664.1) & 0.0 & 97.87 \\
\hline Burkholderia ks20_b69 & MW041147 & B. catarinensis (NR_153664.1) & 0.0 & 97.62 \\
\hline Burkholderia ks20_b71 & MW040834 & B. catarinensis (NR_153664.1) & 0.0 & 99.13 \\
\hline Burkholderia ks20_b31 & MW040833 & B. catarinensis (NR_153664.1) & 0.0 & 98.50 \\
\hline Burkholderia ks20_b16 & MW041149 & B. catarinensis (NR_153664.1) & 0.0 & 99.15 \\
\hline Burkholderia ks20_b74 & MW040835 & B. catarinensis (NR_153664.1) & 0.0 & 98.91 \\
\hline Burkholderia ks20_b12 & MW040832 & B. catarinensis (NR_153664.1) & 0.0 & 98.54 \\
\hline Pseudomonas ks20_b65 & MW040836 & Pseudomonas helleri (NR_148763.1) & 0.0 & 97.86 \\
\hline Penicillium ks20_f10 & MW040805 & Penicillium thomii (NR_077159.1) & $2 e-173$ & 99.11 \\
\hline Penicillium ks20_f20 & MW040810 & Penicillium bialowiezense (NR_165994.1) & $1 e-165$ & 96.58 \\
\hline Penicillium ks20_f52 & MW040812 & Penicillium montanense (NR_138270.1) & $2 e-163$ & 98.76 \\
\hline Penicillium ks20_f54 & MW040813 & Penicillium thomii (NR_077159.1) & $8 e-167$ & 97.66 \\
\hline Penicillium ks20_f14 & MW040806 & Penicillium daejeonium (NR_158791.1) & $1 e-169$ & 98.23 \\
\hline Penicillium ks20_f15 & MW040807 & Penicillium kiamaense (NR_137899) & $2 e-168$ & 99.69 \\
\hline Penicillium ks20_f18 & MW040808 & Penicillium malachiteum (NR_120271.1) & 0.0 & 99.15 \\
\hline Penicillium ks20_f19 & MW040809 & Penicillium montanense (NR_138270.1) & $5 e-174$ & 98.55 \\
\hline Penicillium ks20_f30 & MW040811 & Penicillium montanense (NR_138270.1) & $1 \mathrm{e}-175$ & 98.29 \\
\hline
\end{tabular}

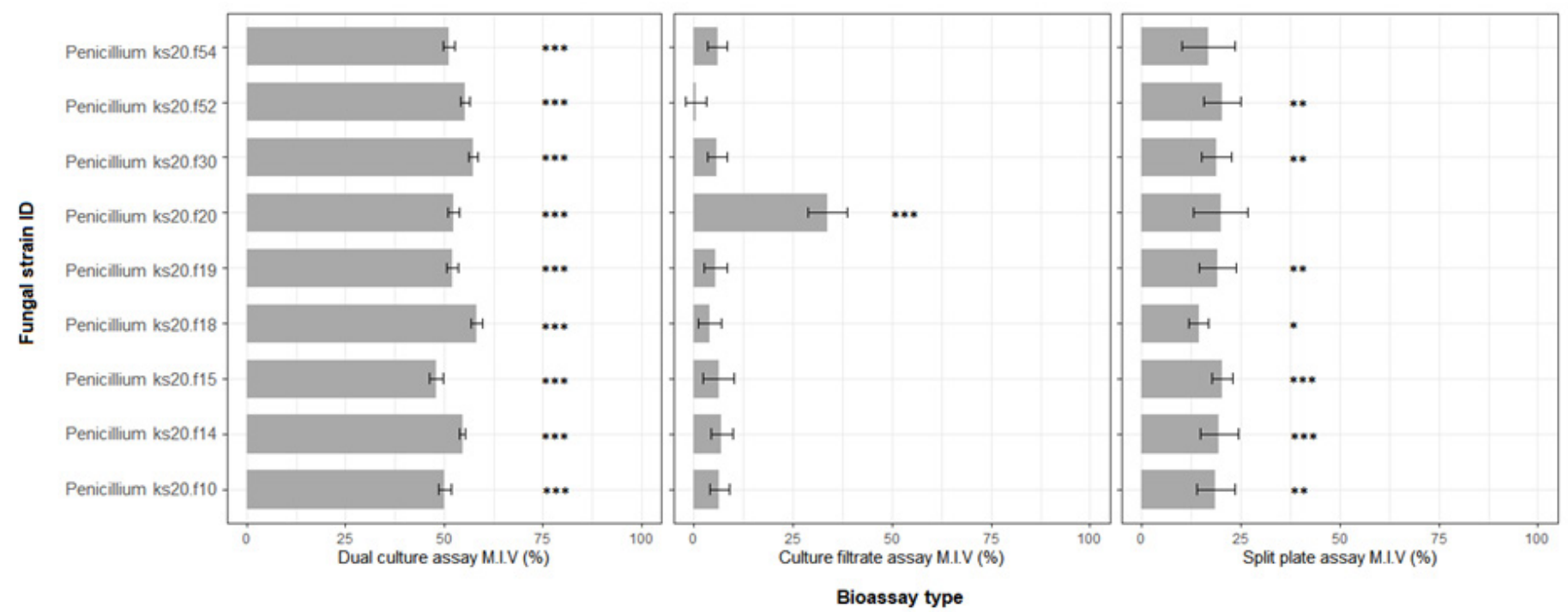

Figure 1 The mean \pm SE mycelial inhibition values (MIV \%) of the in vitro bioassays used to assess the inhibition of fungal isolates against Phytophthora agathidicida. Student T tests were used to identify isolates with significantly higher MIV compared to controls ( $*$ is $p$-value $<0.05,{ }^{* *}$ is $p$-value $<0.01$ and ${ }^{* * *}$ is $p$-value $<0.001$ ). 

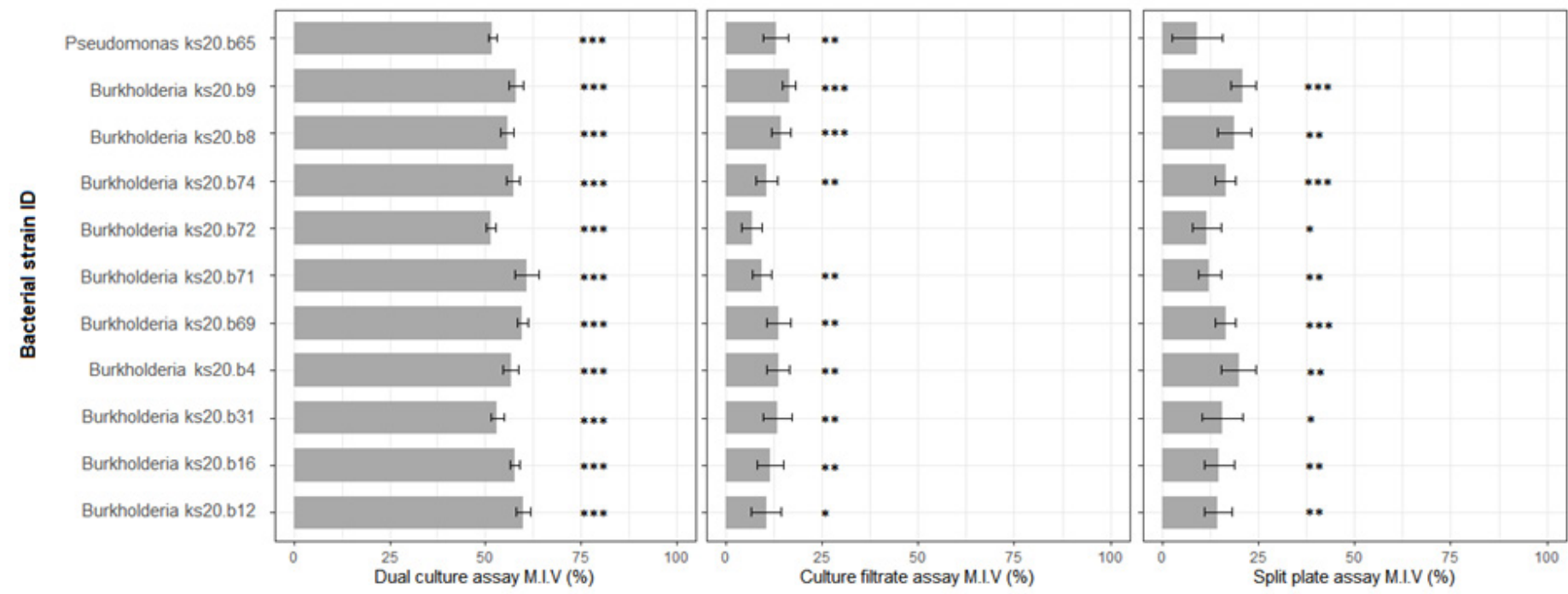

Bioassay type

Figure 2 The mean \pm SE mycelial inhibition values (MIV \%) of the in vitro bioassays used to assess the inhibition of bacterial isolates against Phytophthora agathidicida. Student T tests were used to identify isolates with significantly higher MIV compared to controls ( $*$ is $p$-value $<0.05,{ }^{* *}$ is $p$-value $<0.01$ and ${ }^{* * *}$ is $p$-value $<0.001$ ).

overgrew the mycelium of $P$ agathidicida in dual culture (Fig. S7, Supplementary Materials).

\section{Culture filtrate bioassays}

The culture filtrates of only one fungal isolate, Penicillium ks20_f20, significantly reduced the mycelial growth of Phytophthora agathidicida when compared with controls (mean MI: $33.72 \pm 4.95 \%$; $p$-value < 0.001, Fig. 1). As well as inhibiting mycelial growth, the culture filtrates of Penicillium ks20_f20 noticeably reduced the mycelial density of Phytophthora agathidicida (Fig. 3).

Burkholderia ks20_b72 was the only bacterial isolate that did not significantly reduce $P$. agathidicida mycelial growth ( $p$-value $>0.05)$. As shown in Fig. 2, the culture filtrates of all other 10 bacterial isolates significantly reduced $P$. agathidicida mycelial growth compared to controls ( $p$-value $<0.05)$. Bacterial isolates whose filtrates had the highest mean MI value (\%) were Burkholderia ks20_b9

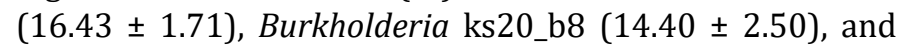
Burkholderia ks20_b69 (13.69 \pm 3.19).

\section{Split plate bioassays}

When tested using split plate bioassays, seven Penicillium isolates significantly reduced Phytophthora agathidicida mycelial growth compared with controls ( $p$-value $<0.05$, Fig. 1). Isolates with the highest mean MI values (\%) were Penicillium ks20_f15 (20.26 \pm 2.64$)$ and Penicillium ks20_f52 (20.33 \pm 4.76). Penicillium ks20_f20 and Penicillium ks20_

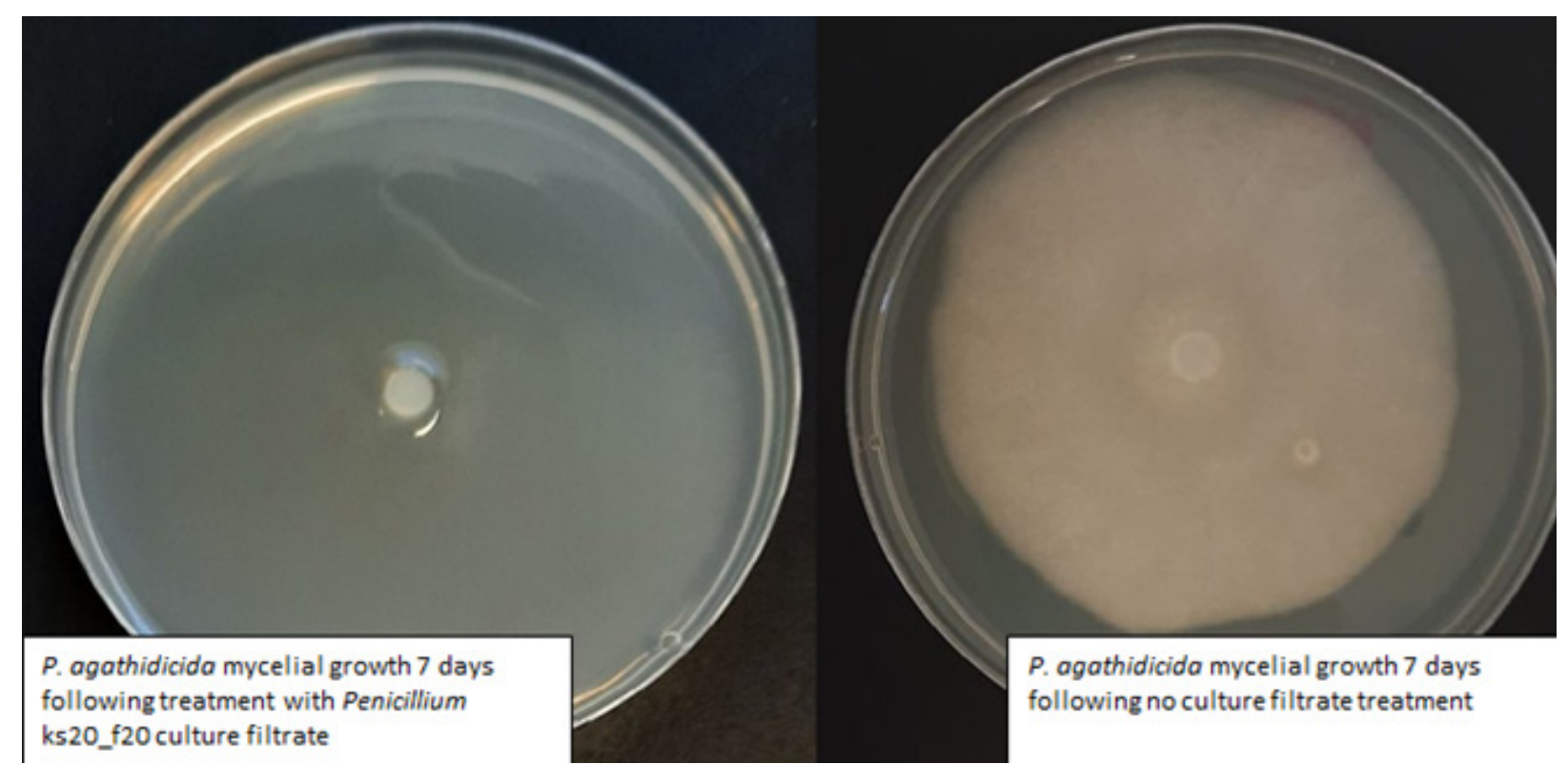

Figure 3 The mycelial growth of Phytophthora agathidicida on day 7 following culture filtrate treatment with Penicillium ks20_f20 versus the mycelial growth of Phytophthora agathidicida on day 7 that had no culture filtrate treatment. 
f54 did not significantly reduce Phytophthora agathidicida mycelial growth compared to controls ( $p$-value $>0.05)$.

Except for Pseudomonas ks20_b65, all bacterial isolates significantly reduced Phytophthora agathidicida mycelial growth compared to controls when tested using split plate bioassays ( $p$-value $<0.05$, Fig. 2). The highest mean MI values (\%) were found for Burkholderia ks20_b9 (21.03 \pm 3.17) and Burkholderia ks20_b4 (19.87 \pm 4.49 ).

\section{VOC profiles of microbial isolates}

From the results of the HS SPME-GC-MS analysis, we putatively identified five volatile organic compounds (VOCs) produced by $P$. agathidicida, which were 2-phenylethanol $(0.65 \pm 0.07 \%)$; methyl salicylate $(0.31 \pm 0.14 \%) ; 2,2$, 4-trimethyl-1,3-pentanediol di-isobutyrate (0.35 $\pm 0.02 \%)$; and 2,5-di-tert-butyl-1,4-benzoquinone (0.42 $\pm 0.09 \%)$. None of these VOCs were putatively identified to be produced by the fungal or bacterial isolates subsequently analysed
(Fig. 4 and Fig. 5). Based on these results, no VOCs produced by the fungal and bacterial isolates were also produced by $P$. agathidicida.

Across all the fungal isolates analysed; 32 different VOCs were putatively identified (Fig. 4). These covered six chemical classes - sesquiterpenoids, monoterpenoids, ketones, hydrocarbons, fatty alcohols, and benzenoids (Fig. S8, Supplementary Materials). We did not detect any identifiable VOCs from Penicillium ks20_f20. This finding is consistent with the results of the split plate bioassays, which found that this isolate did not significantly inhibit Phytophthora agathidicida mycelial growth (Fig. 1). Although Penicillium ks20_f54 did not significantly inhibit $P$. agathidicida mycelial growth when tested using split plate bioassays (Fig. 1), three identifiable VOCs produced by this isolate were detected(Fig. 4). Two of these VOCs, 3-octanone and 1-octen-3-ol, were also produced by Penicillium ks20_ f30. Therefore, these two VOCs are unlikely to be responsible for the mycelial inhibition observed by Penicillium ks20_f30.

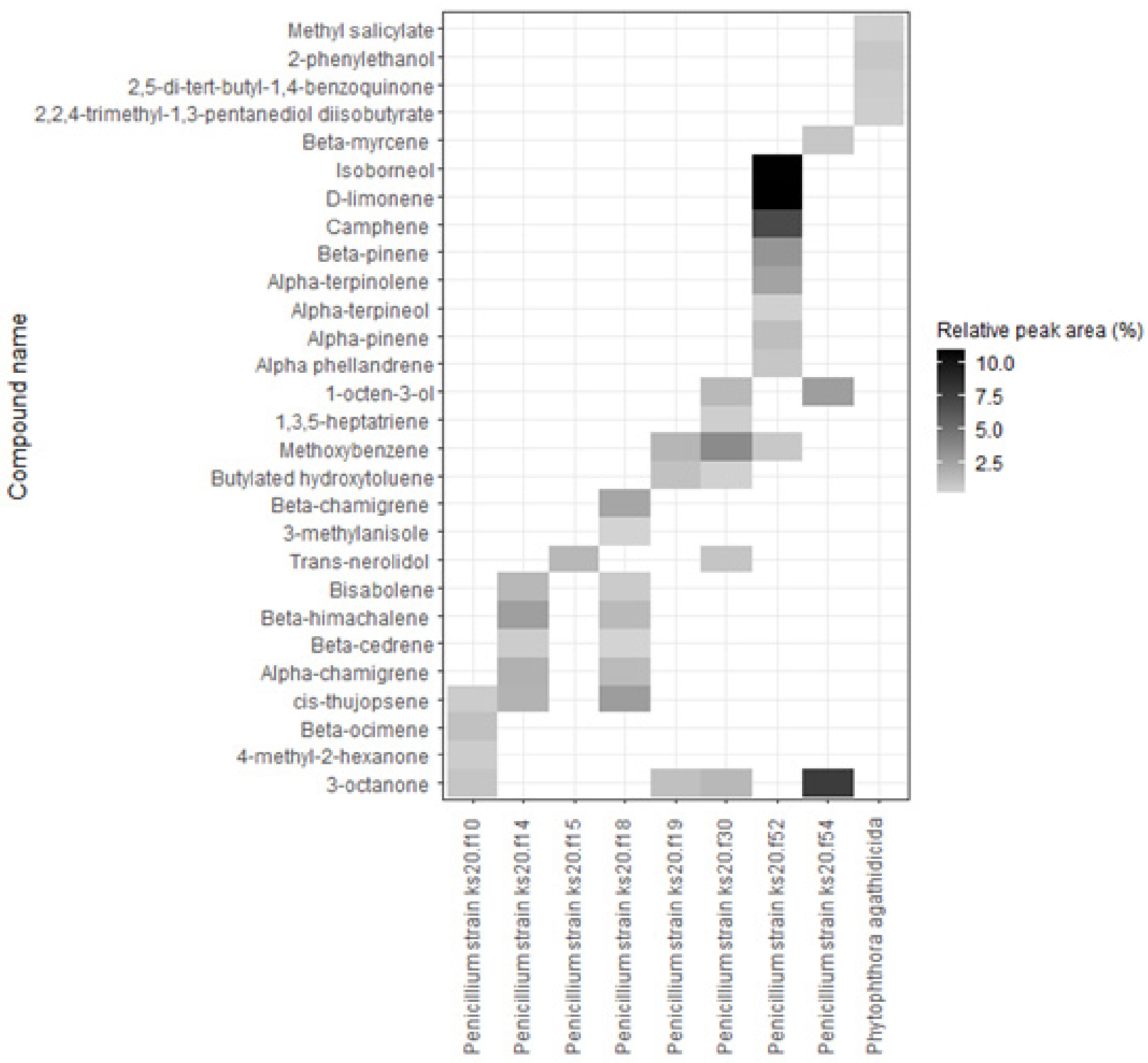

Figure 4 The peak areas (\%) of the putatively identified VOCs released by the Penicillium isolates and Phytophthora agathidicida (which was functioning as a control) relative to the total peak area for all compounds. For all samples, siloxane contaminants from the vials constituted most of the VOCs detected in the headspace (not shown). Penicillium ks20_f20 is not shown in this figure as no identifiable VOCs were detected from this isolate. 


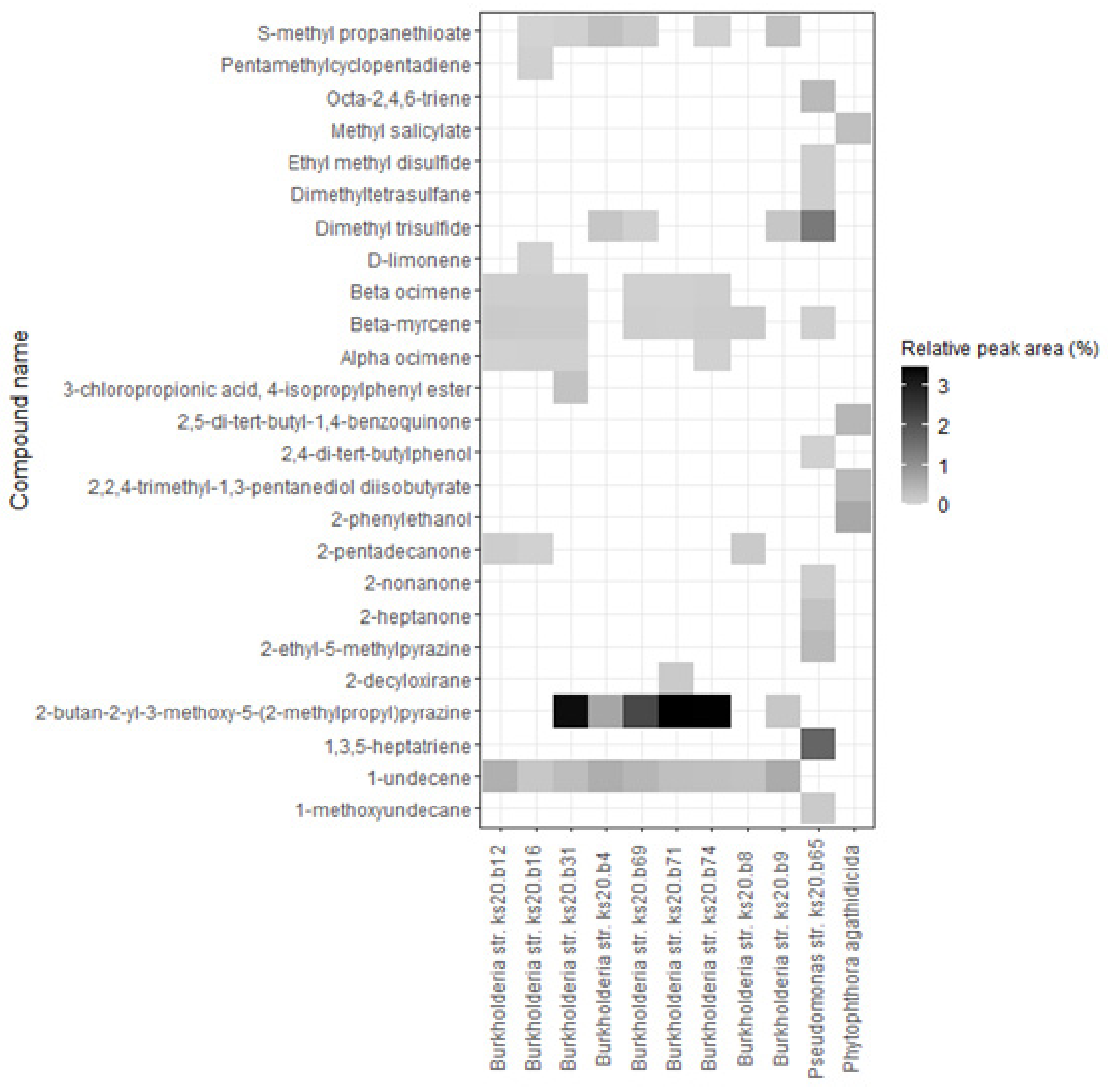

Figure 5 The peak areas (\%) of the putatively identified VOCs released by the Burkholderia isolates and Phytophthora agathidicida (which was functioning as a control) relative to the total peak area for all compounds. For all samples, siloxane contaminants from the vials constituted most of the VOCs detected in the headspace (not shown). Paraburkholderia ks20_b72 is not shown on this figure as no identifiable VOCs were detected from this isolate.

Across all the bacterial isolates analysed; 29 VOCs were putatively identified (Fig. 5). These covered 13 chemical classes - alkenes, benzenoids, epoxides, fatty acyls, hydrocarbons, ketones, monoterpenoids, organic disulphides, organic oxides, organic trisulfides, pyrazines, sesquiterpenoids, and thiocarboxylic acids (Fig. S8, Supplementary Materials). The alkene compound 1-undecene was putatively identified to be produced in the head space from all the Burkholderia isolates. Additionally, the pyrazine compound 2-butan-2-yl-3-methoxy-5-(2methylpropyl) pyrazine had a high relative peak area in several of the Burkholderia isolates (Fig. 5). Based on our methods, we were not able to identify any compounds produced by Paraburkholderia ks20_b72. Except for betamyrcene and dimethyl trisulphide, no identifiable VOCs produced by Pseudomonas ks20_b65 were produced by the other Burkholderia isolates (Fig. 5). Pseudomonas ks20_b65 did not significantly inhibit Phytophthora agathidicida mycelial growth in split plate bioassays, thus these results suggest that this strain is not inhibiting $P$. agathidicida through the production of inhibitory VOCs.

\section{DISCUSSION}

When tested using dual culture bioassays, microbial isolates belonging to the genera Penicillium, Burkholderia, Paraburkholderia, and Pseudomonas significantly inhibited the mycelial growth of Phytophthora agathidicida. It is likely that multiple isolates of the same species were obtained but further, more detailed genomic analysis and morphological 
identification are required in order to assign isolates to species level and this work was outside the scope of the current study. Several isolates inhibited $P$. agathidicida in culture filtrate and split plate bioassays, which suggests that the production of diffusible and volatile compounds may be factors contributing to inhibition. However, the inhibition of $P$. agathidicida was much lower in culture filtrate and split plate bioassays than in dual culture bioassays. A similar finding was observed by Elshafie et al. (2012) who found a greater inhibition of Phytophthora cactorum by Burkholderia gladioli pv. agaricicola in dual culture bioassays compared to culture filtrate treatments. The greater inhibition observed in dual culture bioassays may be due to the synergistic effects of multiple modes of antagonism acting against $P$. agathidicida (i.e. microbial competition combined with the production of anti-microbial compounds), rather than a single mode of action being responsible for most of the observed inhibition.

\section{Burkholderia isolates display strong inhibition towards P. agathidicida}

In each of the three bioassays used to test for inhibition, all nine Burkholderia isolates significantly inhibited the mycelial growth of $P$. agathidicida. Burkholderia species have previously been reported to antagonise a wide range of pathogens, including Phytophthora species (Elshafie et al. 2012; Sopheareth et al. 2013; Kong et al. 2020). When screened using dual culture bioassays, there was a clear zone of inhibition present on agar and no isolates came into direct contract with $P$. agathidicida. Therefore, it is unlikely that inhibition was a result of direct mycoparasitism or microbial competition.

All Burkholderia isolates significantly inhibited the growth of $P$. agathidicida in split plate and culture filtrate bioassays, albeit at a lower level of inhibition than in dual culture. Despite inhibition being lower in the culture filtrate bioassays, these results support that compounds released by the bacterial isolates may be contributing to inhibition. This notion is supported by the clear zones of inhibition observed in the dual culture bioassays. Future research may wish to identify if inhibitory compounds are being released by the bacteria and diffusing through the agar. The production of secondary metabolites such as siderophores, antibiotics, hydrolytic enzymes, and biosurfactants are known to contribute to the suppression of pathogenic fungi by bacteria (Neeraja et al. 2010). Furthermore, Burkholderia species have been demonstrated to produce a wide range of anti-microbial secondary metabolites (Li et al. 2002; Vial et al. 2007; Depoorter et al. 2016). Further research that characterises the secondary metabolites produced by the Burkholderia isolates, both on solid agar and in culture filtrate form, is required to understand the mechanisms driving inhibition of $P$. agathidicida by these strains.

The results of the culture filtrate bioassays did not provide any evidence that Paraburkholderia ks20_b72 produced compounds that are inhibitory towards Phytophthora agathidicida. However, this isolate was observed to significantly inhibit $P$. agathidicida in dual culture and split plate bioassays. Similarly, despite being found to produce a diverse range of VOCs by HS SPME-GC-MS analysis,
Pseudomonas ks20_b65 did not significantly inhibit $P$. agathidicida when tested using split plate bioassays. This contrasts with previous research by Hunziker et al. (2015) and De Vrieze et al. (2015), who identified that Pseudomonas isolates can produce VOCs with anti-Phytophthora activities. Pseudomonas ks20_b65 significantly inhibited Phytophthora agathidicida in dual culture and culture filtrate bioassays, suggesting the production of other anti-microbial compounds may be a potential mode of action by this strain. Previous studies have identified strains of Pseudomonas that produce a wide range of inhibitory compounds active against phytopathogens such as siderophores, broadspectrum antibiotics, lipopeptides, polyketides, and biosurfactants (Nielsen et al. 2006; Caulier et al. 2018; Arora et al. 2008; Tran et al. 2007). Further research is needed to identify the modes of action contributing to the inhibition of P. agathidicida by Pseudomonas ks20_b65 and Paraburkholderia ks20_b72 observed in dual culture.

\section{Penicillium isolates were variable in their inhibition of P. agathidicida}

Several isolates of Penicillium overgrew the mycelium of $P$. agathidicida in dual culture, which suggests that these isolates may have inhibited $P$. agathidicida by having a more competitive growth rate on agar which physically limited the growth of $P$. agathidicida (Bunbury-Blanchette \& Walker 2019). These results align with the findings of Byers et al. (2020), which found that the relative abundance of Penicillium was significantly higher in soils associated with healthy, asymptomatic kauri compared to symptomatic kauri expressing the symptoms of dieback disease. For biological control agents whose main mode of action is through competition, sustaining high population levels in the soil environment is essential for them to suppress target pathogens (Alabouvette et al. 2006). Quite often, microbial antagonists fail to confer disease suppression when applied in the field as they cannot compete with the resident soil microbiota to successfully establish within the rhizosphere (Expósito et al. 2017). Penicillium species are well-adapted and highly competitive members of the soil environment and have been demonstrated to antagonise a variety of plant pathogens (Nicoletti \& De Stefano 2012). Therefore, the identification of Penicillium isolates demonstrating inhibition towards Phytophthora agathidicida is promising in regard to their practical application in the field. Biological control agents (BCAs) with non-chemical modes of action (i.e. nutrient competition) have a lower likelihood of pathogen resistance developing. In addition, their ecotoxicological risk and associated risk assessments required to permit their application are much lower as they are inhibiting pathogens through general ecological processes rather than the production of anti-microbial compounds (Köhl et al. 2019).

The culture filtrates of Penicillium ks20_f20 strongly inhibited Phytophthora agathidicida and this isolate produced a clear zone of inhibition in dual culture. However, the limitations of quantifying inhibition by measuring the reduction in the mycelial growth of $P$. agathidicida was evident when assessing the inhibitory potential of this strain, as measurements of mycelial diameter did not 
reflect the large reductions in the mycelial density of $P$. agathidicida. Future research should measure the impact of each $P$. agathidicida isolate on sporangia production and zoospore release to better quantify their inhibitory potential. Nonetheless, our results support that Penicillium ks20_f20 produced anti-microbial compounds inhibitory towards Phytophthora agathidicida. As with isolates of Burkholderia, more research is required to characterise these compounds with potential anti-microbial action, as it is important to fully understand their mode of action before they can be appropriately and effectively applied in the field for biocontrol (Spadaro \& Gullino 2005).

\section{Contribution of microbial VOCs to the inhibition of $P$. agathidicida}

All the Burkholderia isolates inhibited the growth of $P$. agathidicida in split plate bioassays, suggesting they may be releasing VOCs with inhibitory properties against $P$. agathidicida. The putatively identified compound 1-undecene was produced by all the Burkholderia isolates. This compound has previously been found to inhibit the mycelial growth, sporangia formation and zoospore release of Phytophthora infestans (Hunziker et al. 2015). Another putatively identified VOC emitted by several of the Burkholderia isolates was 2-butan-2-yl-3-methoxy-5(2-methylpropyl) pyrazine. Although this compound has not been studied for its anti-microbial properties, other pyrazine VOCs (i.e. 2, 5-dimethyl pyrazine and 2-methoxy-3methyl pyrazine) have previously been identified to inhibit the growth of Phytophthora infestans and P. capsici (Munjal et al. 2016; Lazazzara et al. 2017). Several Burkholderia isolates were identified to produce the two monoterpenoid compounds alpha ocimene and beta ocimene. TenorioSalgado et al. (2013) identified ocimene compounds to be produced by isolates of Burkholderia tropica that inhibited several plant pathogens, although inhibition was not tested for Phytophthora. In addition, ocimene compounds were identified as components of plant essential oils that were able to significantly inhibit the mycelial growth of Phytophthora capsici, P. drechsleri, and P. melonis (Amini et al. 2016).

Most Penicillium isolates isolated in this study significantly inhibited P. agathidicida in split plate bioassays. Many of the VOCs produced by these isolates were putatively identified as terpenoids, ketones, and benzenoids. However, the scientific knowledge regarding the inhibitory roles of VOCs produced by Penicillium against fungal plant pathogens is limited as Penicillium species have been more thoroughly researched for their production of anti-bacterial compounds (Rouissi et al. 2013). In addition, unlike the isolates of Burkholderia, no VOCs were identified to be consistently produced by the Penicillium isolates that inhibited Phytophthora agathidicida.

To characterise the VOC profile of each isolate, this study incubated each microbial antagonist in isolation (i.e. not in the presence of $P$. agathidicida) prior to HS SPME-GCMS analysis. However, this did not allow us to detect novel VOCs which may be produced by the isolates when in the presence of $P$. agathidicida. When interacting under a shared environment, the production of microbial VOCs can mediate interspecies communication (Schmidt et al. 2015).
Furthermore, the release of microbial VOCs with roles in antibiosis and signalling can serve as an important regulatory mechanism under resource competitive environments (Effmert et al.2012). When exposed P. agathidicida, the VOCs released by each isolate may have been different to what was characterised when using our methods. Therefore, future research should aim to characterise the VOC profiles of each microbial antagonist when in the presence of $P$. agathidicida.

\section{CONCLUSIONS}

This study identified isolates belonging to the genera Burkholderia and Penicillium that exhibit different modes of action against $P$. agathidicida, and warrant further research as candidates for its biocontrol. As all isolates of Burkholderia were able to inhibit $P$. agathidicida mycelial growth without establishing direct contact, the mode of inhibition may be through production of diffusible and volatile inhibitory compounds. Many of the Penicillium isolates had a fast growth rate that restricted the growth of Phytophthora agathidicida on agar, suggesting that microbial competition is a likely mode of inhibition. Further research should assess the synergistic effects of these different microbial isolates, as combining different strains of microbial antagonists can often provide a higher level of disease suppression as multiple different modes of antagonism are acting against the target pathogen (Spadaro \& Gullino 2005; De Vrieze et al. 2018).

HS SPME-GC-MS analysis putatively identified several VOCs, such as 1-undecene, as being produced by many of the Burkholderia isolates. Further research is required to more accurately identify these VOCs by comparing their retention times and mass spectra with pure reference standards of the respective compounds. Furthermore, the direct effects of these VOCs in their pure form on the growth of P. agathidicida need to be assessed to identify if they are responsible for the inhibition observed in this study. The cultures filtrates of all Burkholderia isolates and one Penicillium isolate inhibited the growth of Phytophthora agathidicida. The compounds present in these culture filtrates need to be characterised so that their direct impacts on the growth of $P$. agathidicida mycelia can be assessed.

\section{ACKNOWLEDGEMENTS}

This project was supported by the New Zealand Tertiary Education Commission CoRE grant to the Bio-Protection Research Centre. Thank you to Te Roroa Iwi for permitting access to Waipoua Forest which allowed for the discovery of these microbial isolates.

\section{ADDITIONAL FILES}

Supplementary Methods

Supplementary Materials

\section{REFERENCES}

Alabouvette C, Olivain C, Steinberg C 2006. Biological control of plant diseases: the European situation. European 
Journal of Plant Pathology 114: 329-341. https://doi. org/10.1007/s10658-005-0233-0

Ahmed AS, Sánchez CP, Candela ME 2000. Evaluation of induction of systemic resistance in pepper plants (Capsicum annuum) to Phytophthora capsici using Trichoderma harzianum and its relation with capsidiol accumulation. European Journal of Plant Pathology 106: 817-824.

Amini J, Farhang V, Javadi T, Nazemi J 2016. Antifungal effect of plant essential oils on controlling Phytophthora species. The Plant Pathology Journal 32: 16. https://doi. org/10.5423/PP..0A.05.2015.0091

Arora NK, Khare E, Oh JH, Chul S 2008. Diverse mechanisms adopted by fluorescent Pseudomonas PGC2 during the inhibition of Rhizoctonia solani and Phytophthora capsici. World Journal of Microbiology and Biotechnology 24: 581-585. https://doi.org/10.1007/s11274-007-9505-5

BaeS-J, Mohanta TK, Chung JY, Ryu M, Park G, Shim S, Hong S-B, Seo H, Bae D-W, Bae I, Kim J-J, Bae H 2016. Trichoderma metabolites as biological control agents against Phytophthora pathogens. Biological Control 92: 128138. https://doi.org/10.1016/j.biocontrol.2015.10.005

Beever RE, Waipara NW, Ramsfield TD, Dick MA, Horner IJ 2009. Kauri (Agathis australis) under threat from Phytophthora. Phytophthoras in Forests and Natural Ecosystems 74: 74-85.

Bellgard SE, Padamsee M, Probst C, Lebel T, Williams S 2016. Visualizing the early infection of Agathis australis by Phytophthora agathidicida, using microscopy and fluorescent in situ hybridization. Forest Pathology 46: 622-631. https://doi.org/10.1111/efp.12280

Bhusal B, Mmbaga M 2020. Biological control of Phytophthora blight and growth promotion in sweet pepper by Bacillus species. Biological Control 150: 104373. https://doi. org/10.1016/j.biocontrol.2020.104373

Bitas V, Kim H-S, Bennett JW, Kang S 2013. Sniffing on microbes: diverse roles of microbial volatile organic compounds in plant health. Molecular Plant-Microbe Interactions 26: 835-843. https://doi.org/10.1094/ MPMI-10-12-0249-CR

Bradshaw RE, Bellgard SE, Black A, Burns BR, Gerth ML, McDougal RL, Scott PM, Waipara NW, Weir BS, Williams NM, Winkworth RC, Ashcroft T, Bradley EL, Dijkwel PP, Guo Y, Lacey RF, Mesarich CH, Panda P, Horner IJ 2020. Phytophthora agathidicida: research progress, cultural perspectives and knowledge gaps in the control and management of kauri dieback in New Zealand. Plant Pathology 69: 3-16. https://doi.org/10.1111/ ppa.13104

Bunbury-Blanchette AL, Walker AK 2019. Trichoderma species show biocontrol potential in dual culture and greenhouse bioassays against Fusarium basal rot of onion. Biological Control 130: 127-135. https://doi. org/10.1016/j.biocontrol.2018.11.007

Byers A-K, Condron L, O'Callaghan M, Waipara N, Black A 2020. Soil microbial community restructuring and functional changes in ancient kauri (Agathis australis) forests impacted by the invasive pathogen Phytophthora agathidicida. Soil Biology and Biochemistry 150: 108016. https://doi.org/10.1016/j.soilbio.2020.108016

Caulier S, Gillis A, Colau G, Licciardi F, Liépin M, Desoignies N, Modrie P, Legrève A, Mahillon J, Bragard C 2018. Versatile antagonistic antagonistic activities of soilborne borne Bacillus spp. and Pseudomonas spp. against Phytophthora infestans and other potato pathogens. Frontiers in Microbiology 9: 143-143. https://doi. org/10.3389/fmicb.2018.00143

de Boer W, Li X, Meisner A, Garbeva P 2019. Pathogen suppression by microbial volatile organic compounds in soils. FEMS Microbiology Ecology 95: fiz105. https:// doi.org/10.1093/femsec/fiz105

De Vrieze M, Germanier F, Vuille N, Weisskopf L 2018. Combining different potato-associated Pseudomonas strains for improved biocontrol of Phytophthora infestans. Frontiers in Microbiology 9: 2573. https://doi. org/10.3389/fmicb.2018.02573

De Vrieze M, Pandey P, Bucheli TD, Varadarajan AR, Ahrens $\mathrm{CH}$, Weisskopf L 2015. Volatile organic compounds from native potato-associated Pseudomonas as potential antioomycete agents. Frontiers in Microbiology 6: 1295. https://doi.org/10.3389/fmicb.2015.01295

Depoorter E, Bull MJ, Peeters C, Coenye T, Vandamme P, Mahenthiralingam E 2016. Burkholderia: an update on taxonomy and biotechnological potential as antibiotic producers. Applied Microbiology and Biotechnology 100: 5215-5229. https://doi.org/10.1007/s00253016-7520-x

Dick M, Kimberley M 2013. Deactivation of oospores of Phytophthora taxon Agathis. MPI Contract No. 15575. Rotorua, New Zealand: Scion. https://www. kauriprotection.co.nz/media/1633/2013-15775deactivation-of-oospores-of-phytophthora-taxonagathis-dick.pdf

Djoumbou Feunang Y, Eisner R, Knox C, Chepelev L, Hastings J, Owen G, Fahy E, Steinbeck C, Subramanian S, Bolton E, Greiner R, Wishart DS 2016. ClassyFire: automated chemical classification with a comprehensive, computable taxonomy. Journal of Cheminformatics 8: 61. https://doi.org/10.1186/s13321-016-0174-y

Effmert U, Kalderás J, Warnke R, Piechulla B 2012. Volatile mediated interactions between bacteria and fungi in the soil. Journal of Chemical Ecology 38:665-703. https:// doi.org/10.1007/s10886-012-0135-5

Elshafie HS, Camele I, Racioppi R, Scrano L, Iacobellis NS, Bufo SA 2012. In vitro antifungal activity of Burkholderia gladioli pv. agaricicola against some phytopathogenic fungi. International Journal of Molecular Sciences 13: $16291-16302 . \quad$ https://doi.org/10.3390/ ijms131216291

Elsherbiny EA, Amin BH, Aleem B, Kingsley KL, Bennett JW 2020. Trichoderma volatile organic compounds as a biofumigation tool against late blight pathogen Phytophthora infestans in postharvest potato tubers. Journal of Agricultural and Food Chemistry 68: 81638171. https://doi.org/10.1021/acs.jafc.0c03150 
Expósito RG, de Bruijn I, Postma J, Raaijmakers JM 2017. Current insights into the role of rhizosphere bacteria in disease suppressive soils. Frontiers in Microbiology 8: 2529. https://doi.org/10.3389/fmicb.2017.02529

Fang J, Tsao P 1995. Efficacy of Penicillium funiculosum as a biological control agent against Phytophthora root rots of azalea and citrus. Phytopathology 85: 871-878. https://doi.org/10.1094/Phyto-85-871

Gadgil PD 1974. Phytophthora heveae, a pathogen of kauri. New Zealand Journal of Forestry Science 4: 59-63.

Herewini EM, Scott PM, Williams NM, Bradshaw RE 2018. In vitro assays of Phytophthora agathidicida on kauri leaves suggest variability in pathogen virulence and host response. New Zealand Plant Protection 71: 285288. https://doi.org/10.30843/nzpp.2018.71.127

Horner IJ, Hough EG 2013. Phosphorous acid for controlling Phytophthora taxon Agathis in kauri: glasshouse trials. New Zealand Plant Protection 66: 242-248. https://doi. org/10.30843/nzpp.2013.66.5673

Hunziker L, Bönisch D, Groenhagen U, Bailly A, Schulz S, Weisskopf L 2015. Pseudomonas strains naturally associated with potato plants produce volatiles with high potential for inhibition of Phytophthora infestans. Applied and Environmental Microbiology 81: 821-830. https://doi.org/10.1128/AEM.02999-14

Insam H, Seewald MSA 2010. Volatile organic compounds (VOCs) in soils. Biology and Fertility of Soils 46: 199213. https://doi.org/10.1007/s00374-010-0442-3

Kim SG, Jang Y, Kim HY, Koh YJ, Kim YH 2010. Comparison of microbial fungicides in antagonistic activities related to the biological control of Phytophthora blight in chili pepper caused by Phytophthora capsici. The Plant Pathology Journal 26: e5. https://doi.org/10.5423/ PPI.2010.26.4.340

Köhl J, Kolnaar R, Ravensberg WJ 2019. Mode of action of microbial biological control agents against plant diseases: relevance beyond efficacy. Frontiers in Plant Science 10: 845. https://doi.org/10.3389/ fpls.2019.00845

Kong P, Richardson P, Hong C 2020. Burkholderia sp. SSG is a broad-spectrumantagonistagainstplant diseases caused by diverse pathogens. Biological Control 151: 104380. https://doi.org/10.1016/j.biocontrol.2020.104380

Kumar S, Chowdappa P, Gore R 2018. Volatile organic compounds emitted by Trichoderma harzianum OTPB3 elicites anti fungal activity against Phytophthora infestans and induces plant growth promotion and systemic resistance in tomato. International Journal of Innovative Horticulture 7: 128-138.

Kunova A, Bonaldi M, Saracchi M, Pizzatti C, Chen X, Cortesi P 2016. Selection of Streptomyces against soil borne fungal pathogens by a standardized dual culture assay and evaluation of their effects on seed germination and plant growth. BMC Microbiology 16: 272. https://doi. org/10.1186/s12866-016-0886-1

Lawrence SA, Armstrong CB, Patrick WM, Gerth ML 2017. High-throughput chemical screening identifies compounds that inhibit different stages of the Phytophthora agathidicida and Phytophthora cinnamomi life cycles. Frontiers in Microbiology 8: 1340. https:// doi.org/10.3389/fmicb.2017.01340

Lawrence SA, Burgess EJ, Pairama C, Black A, Patrick WM, Mitchell I, Perry NB, Gerth ML 2019. Mātaurangaguided screening of New Zealand native plants reveals flavonoids from kānuka (Kunzea robusta) with antiPhytophthora activity. Journal of the Royal Society of New Zealand 49: 137-154. https://doi.org/10.1080/03 036758.2019.1648303

Lazazzara V, Perazzolli M, Pertot I, Biasioli F, Puopolo G, Cappellin L 2017. Growth media affect the volatilome and antimicrobial activity against Phytophthora infestans in four Lysobacter type strains. Microbiological Research 201: 52-62. https://doi.org/10.1016/j. micres.2017.04.015

Lemfack MC, Gohlke B-0, Toguem SMT, Preissner S, Piechulla B, Preissner R 2018. mVOC 2.0: a database of microbial volatiles. Nucleic Acids Research 46: D1261-D1265. https://doi.org/10.1093/nar/gkx1016

Li W, Roberts D, Dery P, Meyer S, Lohrke S, Lumsden R, Hebbar K 2002. Broad spectrum anti-biotic activity and disease suppression by the potential biocontrol agent Burkholderia ambifaria BC-F. Crop Protection 21: 129135. https://doi.org/10.1016/S0261-2194(01)00074-6

Ma Y, Chang Z-z, Zhao J-t, Zhou M-g 2008. Antifungal activity of Penicillium striatisporum Pst10 and its biocontrol effect on Phytophthora root rot of chilli pepper. Biological Control 44: 24-31. https://doi.org/10.1016/j. biocontrol.2007.10.005

Majeed A, Muhammad Z, Ullah Z, Ullah R, Ahmad H 2017. Late blight of potato (Phytophthora infestans) I: Fungicides application and associated challenges. Turkish Journal of Agriculture-Food Science and Technology 5: 261-266. https://doi.org/10.24925/turjaf.v5i3.261-266.1038

McDougal R, Bellgard SE, Scott P, Ganley B 2014. Comparison of a real time PCR assay and a soil bioassay technique for detection of Phytophthora taxon Agathis from soil. Kauri Dieback Joint Agency Response. [Report] https://www. kauriprotection.co.nz/media/1632/2014-17101-realtime-pcr-as-diagnostic-tool-comparison-of-a-real-time.pdf

Méndez-Bravo A, Cortazar-Murillo EM, Guevara-Avendaño E, Ceballos-Luna O, Rodríguez-Haas B, Kiel-Martínez AL, Hernández-Cristóbal 0 , Guerrero-Analco JA, Reverchon F 2018. Plant growth-promoting rhizobacteria associated with avocado display antagonistic activity against Phytophthora cinnamomi through volatile emissions. PLoS ONE 13: e0194665-e0194665. https:// doi.org/10.1371/journal.pone.0194665

Munjal V, Nadakkakath AV, Sheoran N, Kundu A, Venugopal V, Subaharan K, Rajamma S, Eapen SJ, Kumar A 2016. Genotyping and identification of broad spectrum antimicrobial volatiles in black pepper root endophytic biocontrol agent, Bacillus megaterium BP17. Biological Control 92: 66-76. https://doi.org/10.1016/j. biocontrol.2015.09.005

Neeraja C, Anil K, Purushotham P, Suma K, Sarma P, 
Moerschbacher BM, Podile AR 2010. Biotechnological approaches to develop bacterial chitinases as a bioshield against fungal diseases of plants. Critical Reviews in Biotechnology 30: 231-241. https://doi.org/10.3109/0 $\underline{7388551.2010 .487258}$

Nicoletti R, De Stefano M 2012. Penicillium restrictum as an antagonist of plant pathogenic fungi. Dynamic Biochemistry, Process Biotechnology and Molecular Biology 6: 61-69.

Nielsen CJ, Ferrin DM, Stanghellini ME 2006. Efficacy of biosurfactants in the management of Phytophthora capsici on pepper in recirculating hydroponic systems. Canadian Journal of Plant Pathology 28: 450-460 https://doi.org/10.1080/07060660609507319

Nieto-Jacobo MF, Steyaert JM, Salazar-Badillo FB, Nguyen DV, Rostás M, Braithwaite M, De Souza JT, Jimenez-Bremont JF, Ohkura M, Stewart A, Mendoza-Mendoza A 2017. Environmental growth conditions of Trichoderma spp. affects indole acetic acid derivatives, volatile organic compounds, and plant growth promotion. Frontiers in Plant Science 8: 102. https://doi.org/10.3389/ fpls.2017.00102

O'Brien PA 2017. Biological control of plant diseases. Australasian Plant Pathology 46: 293-304. https://doi. org/10.1007/s13313-017-0481-4

Okonechnikov K, Golosova O, Fursov M, Team U 2012. Unipro UGENE: a unified bioinformatics toolkit. Bioinformatics 28: 1166-1167. https://doi.org/10.1093/ bioinformatics/bts091

Piechulla B, Degenhardt J 2014. The emerging importance of microbial volatile organic compounds. Plant, Cell \& Environment 37: 811-812. https://doi.org/10.1111/ pce. 12254

Raaijmakers JM, Paulitz TC, Steinberg C, Alabouvette C, Moënne-Loccoz Y 2009. The rhizosphere: a playground and battlefield for soilborne pathogens and beneficial microorganisms. Plant and Soil 321: 341-361. https:// doi.org/10.1007/s11104-008-9568-6

Rouissi W, Ugolini L, Martini C, Lazzeri L, Mari M 2013. Control of postharvest fungal pathogens by antifungal compounds from Penicillium expansum. Journal of Food Protection 76: 1879-1886. https://doi. org/10.4315/0362-028X.JFP-13-072

Schmidt R, Cordovez V, De Boer W, Raaijmakers J, Garbeva $P$ 2015. Volatile affairs in microbial interactions. The ISME Journal 9: 2329-2335. https://doi.org/10.1038/ ismej.2015.42

Sopheareth M, Chan S, Naing KW, Lee YS, Hyun HN, Kim YC, Kim KY 2013. Biocontrol of late blight (Phytophthora capsici) disease and growth promotion of pepper by Burkholderia cepacia MPC-7. The Plant Pathology Journal 29: 67-76. https://doi.org/10.5423/PPJ. OA.07.2012.0114

Spadaro D, Gullino ML 2005. Improving the efficacy of biocontrol agents against soilborne pathogens. Crop Protection 24: 601-613. https://doi.org/10.1016/j. cropro.2004.11.003
Stoppacher N, Kluger B, Zeilinger S, Krska R, Schuhmacher R 2010. Identification and profiling of volatile metabolites of the biocontrol fungus Trichoderma atroviride by HS-SPME-GC-MS. Journal of Microbiological Methods 81: 187-193. https://doi.org/10.1016/j. mimet.2010.03.011

Syed-Ab-Rahman SF, Carvalhais LC, Chua ET, Chung FY, Moyle PM, Eltanahy EG, Schenk PM 2019. Soil bacterial diffusible and volatile organic compounds inhibit Phytophthora capsici and promote plant growth. Science of the Total Environment 692: 267-280. https://doi. org/10.1016/j.scitotenv.2019.07.061

Tenorio-Salgado S, Tinoco R, Vazquez-Duhalt R, CaballeroMellado J, Perez-Rueda E 2013. Identification of volatile compounds produced by the bacterium Burkholderia tropica that inhibit the growth of fungal pathogens. Bioengineered 4: 236-243. https://doi.org/10.4161/ bioe. 23808

Than DJ, Hughes KJD, Boonhan N, Tomlinson JA, Woodhall JW, Bellgard SE, Andrea V 2013. A TaqMan real-time PCR assay for the detection of Phytophthora 'taxon Agathis' in soil, pathogen of kauri in New Zealand. Forest Pathology 43: 324-330. https://doi.org/10.1111/efp.12034

Tran H, Ficke A, Asiimwe T, Höfte M, Raaijmakers JM 2007. Role of the cyclic lipopeptide massetolide A in biological control of Phytophthora infestans and in colonization of tomato plants by Pseudomonas fluorescens. New Phytologist 175: 731-742. https://doi.org/10.1111/ j.1469-8137.2007.02138.x

Vial L, Groleau M-C, Dekimpe V, Deziel E 2007. Burkholderia diversity and versatility: an inventory of the extracellular products. Journal of Microbiology and Biotechnology 17: 1407-1429.

Vinale F, Marra R, Scala F, Ghisalberti EL, Lorito M, Sivasithamparam K 2006. Major secondary metabolites produced by two commercial Trichoderma strains active against different phytopathogens. Letters in Applied Microbiology 43: 143-148. https://doi.org/10.1111/ j.1472-765X.2006.01939.X

Waipara NW, Hill S, Hill LMW, Hough EG, Horner IJ 2013. Surveillance methods to determine tree health, distribution of kauri dieback disease and associated pathogens. New Zealand Plant Protection 66: 235-241. https://doi.org/10.30843/nzpp.2013.66.5671

Weir BS, Paderes EP, Anand N, Uchida JY, Pennycook SR, Bellgard SE, Beever RE 2015. A taxonomic revision of Phytophthora Clade 5 including two new species, Phytophthora agathidicida and P. cocois. Phytotaxa 205: 21. https://doi.org/10.11646/phytotaxa.205.1.2

Widmer TL 2014. Screening Trichoderma species for biological control activity against Phytophthora ramorum in soil. Biological Control 79: 43-48. https:// doi.org/10.1016/j.biocontrol.2014.08.003

Zohara F, Akanda MAM, Paul NC, Rahman M, Islam MT 2016. Inhibitory effects of Pseudomonas spp. on plant pathogen Phytophthora capsici in vitro and in planta. Biocatalysis and Agricultural Biotechnology 5: 69-77. https://doi.org/10.1016/j.bcab.2015.12.009 


\section{Supplementary Methods}

\section{S1. Bacterial and fungal selective agar recipes}

Bacterial selective agar, per litre

- 28 g nutrient agar (Oxoid Ltd., UK)

- $200 \mathrm{mg}$ of pentachloronitrobenzene (PCNB) (Sigma Aldrich, Missouri USA)

- $\quad 400 \mu \mathrm{L}$ of pimaricin (Sigma Aldrich, Missouri USA)

- $50 \mathrm{mg}$ of hymexazol (Tokyo Chemical Industry Co., Ltd, Japan)

Fungal selective agar, per litre

- $39 \mathrm{~g}$ of potato dextrose agar (Oxoid Ltd., UK)

- $250 \mathrm{mg}$ of chloramphenicol (Sigma Aldrich, Missouri USA)

- $90 \mathrm{mg}$ of streptomycin sulphate (Sigma Aldrich, Missouri USA)

- 50 mg of hymexazol (Tokyo Chemical Industry Co., Ltd, Japan)

\section{S2. PCR conditions for Sanger sequencing the $16 S$ rRNA/ITS gene region of microbial isolates}

The 16S rRNA gene region was amplified using the forward and reverse primers 341F/785R (Thijs et al. 2017) and the ITS2 gene region was amplified using the forward and reverse primers ITS3/ITS4 (Op De Beeck et al. 2014) to obtain preliminary genetic information. Each $25 \mu \mathrm{L}$ PCR reaction consisted of $0.5 \mu \mathrm{L}$ of forward and reverse primers at a $10 \mu \mathrm{M}$ concentration, $4 \mu \mathrm{L}$ HOT FIREPol Blend Master Mix (Solis Biodyne, Estonia; https://www.solisbiodyne.com/EN/product/name=HOT-FIREPol-Blend-Master-Mix-Ready-to-Load\&catno=0425-00S25), $19 \mu \mathrm{L}$ of nuclease free water (Invitrogen, Massachusetts USA), and $1 \mu \mathrm{L}$ of DNA. PCR thermocycling conditions were $95^{\circ} \mathrm{C}$ for 12 minutes, followed by 30 cycles of $95^{\circ} \mathrm{C}$ for 15 seconds, $55^{\circ} \mathrm{C}$ for 30 seconds, $72^{\circ} \mathrm{C}$ for 30 seconds and a final extension phase of $75^{\circ} \mathrm{C}$ for 5 minutes. PCR products were run on $1 \%$ agarose gel at $100 \mathrm{~V}$ for 15 minutes to confirm amplification of the desired band.

\section{References: Supplementary Methods}

Op De Beeck M, Lievens B, Busschaert P, Declerck S, Vangronsveld J, Colpaert JV 2014. Comparison and validation of some ITS primer pairs useful for fungal metabarcoding studies. PLoS ONE 9: e97629. https://doi.org/10.1371/journal.pone.0097629

Thijs S, Op De Beeck M, Beckers B, Truyens S, Stevens V, Van Hamme JD, Weyens N, Vangronsveld J 2017. Comparative evaluation of four bacteria-specific primer pairs for 16S rRNA gene surveys. Frontiers in Microbiology 8: 849. https://doi.org/10.3389/fmicb.2017.00494 


\section{Supplementary Materials}

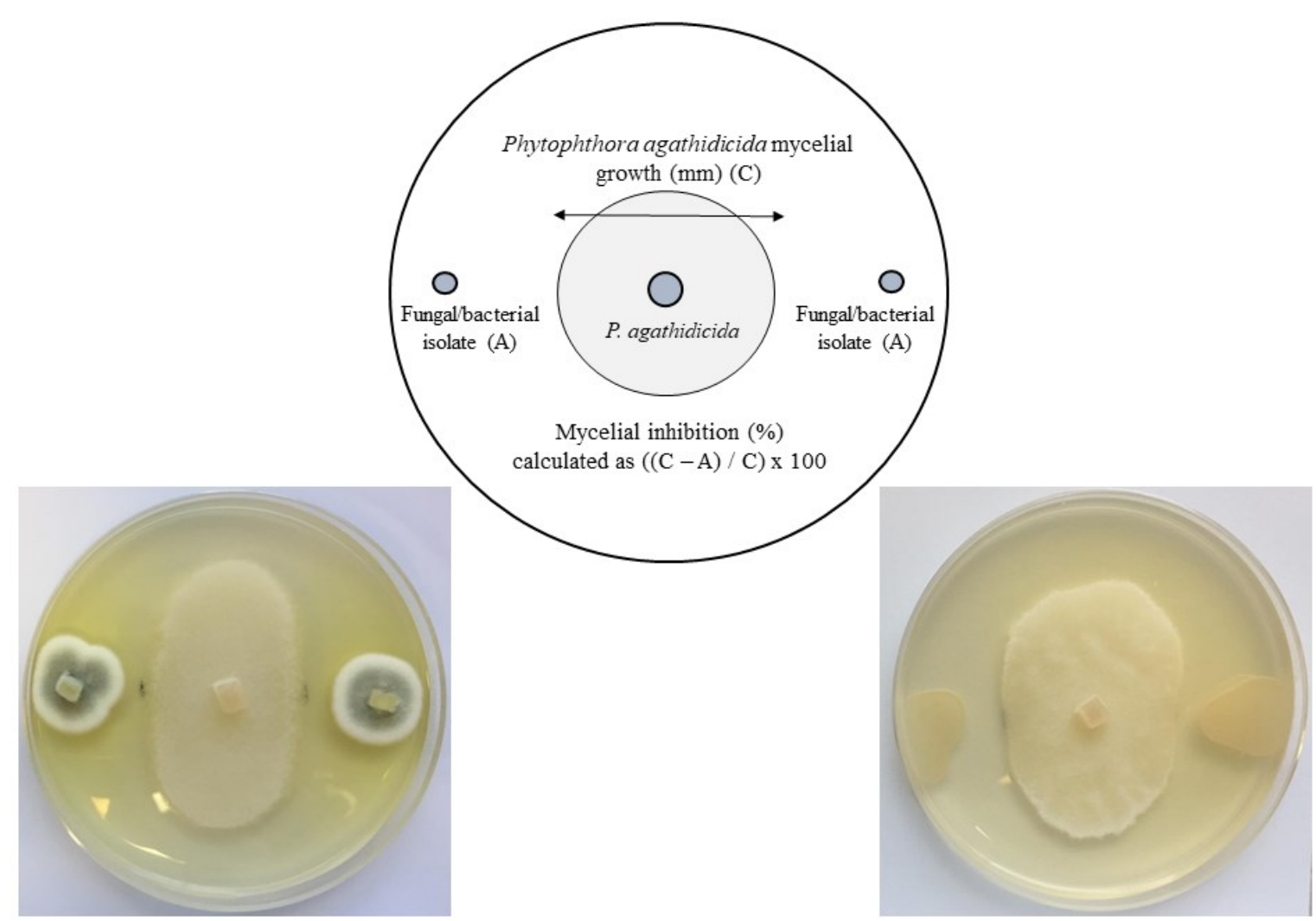

Figure S1 The experimental set up of the dual culture bioassays. Dual culture bioassays were used as the primary form of bioassay to screen fungal and bacterial isolates for their potential to inhibit Phytophthora agathidicida. 


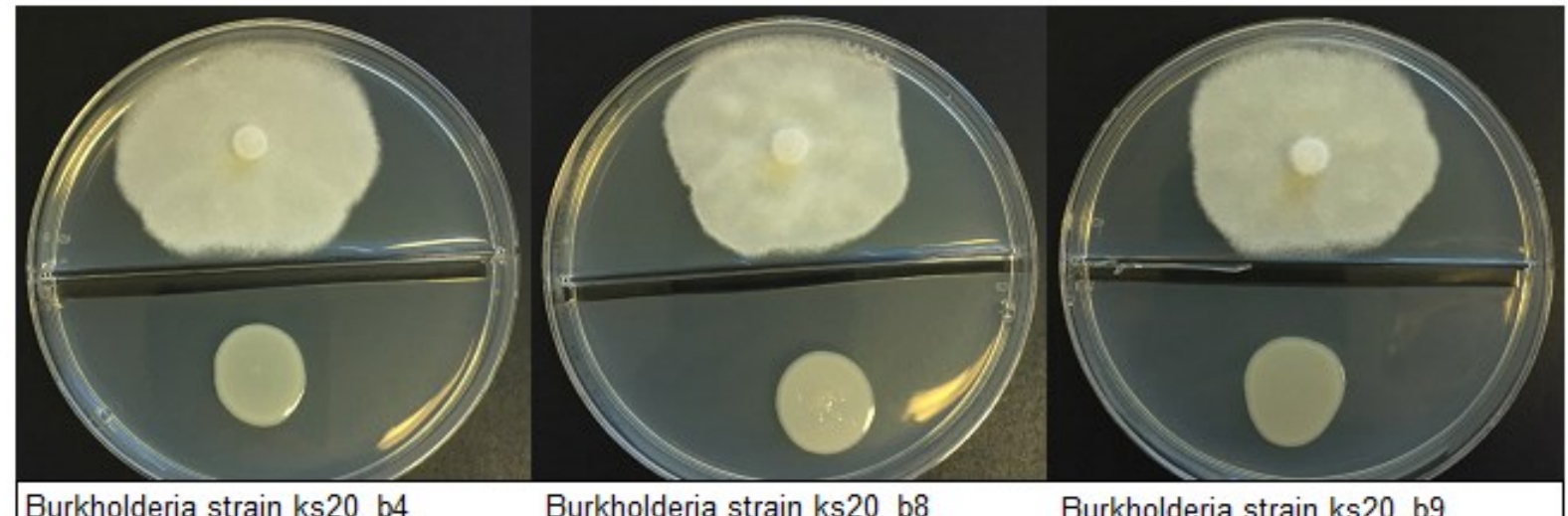

Burkholderia strain ks20 b4

Burkholderia strain ks20 b8

Burkholderia strain ks20_b9
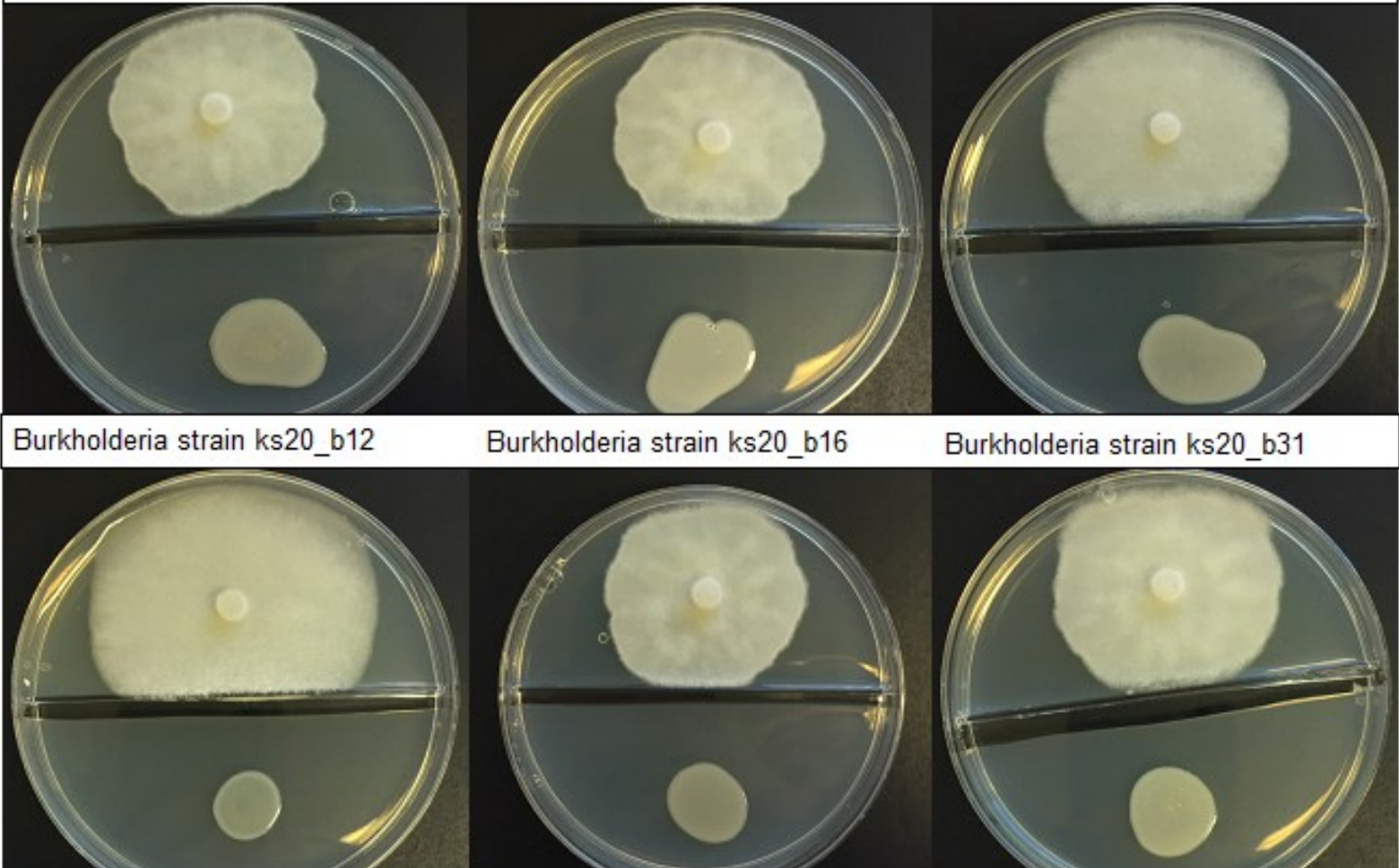

Burkholderia strain ks20_b16

Burkholderia strain ks20_b31
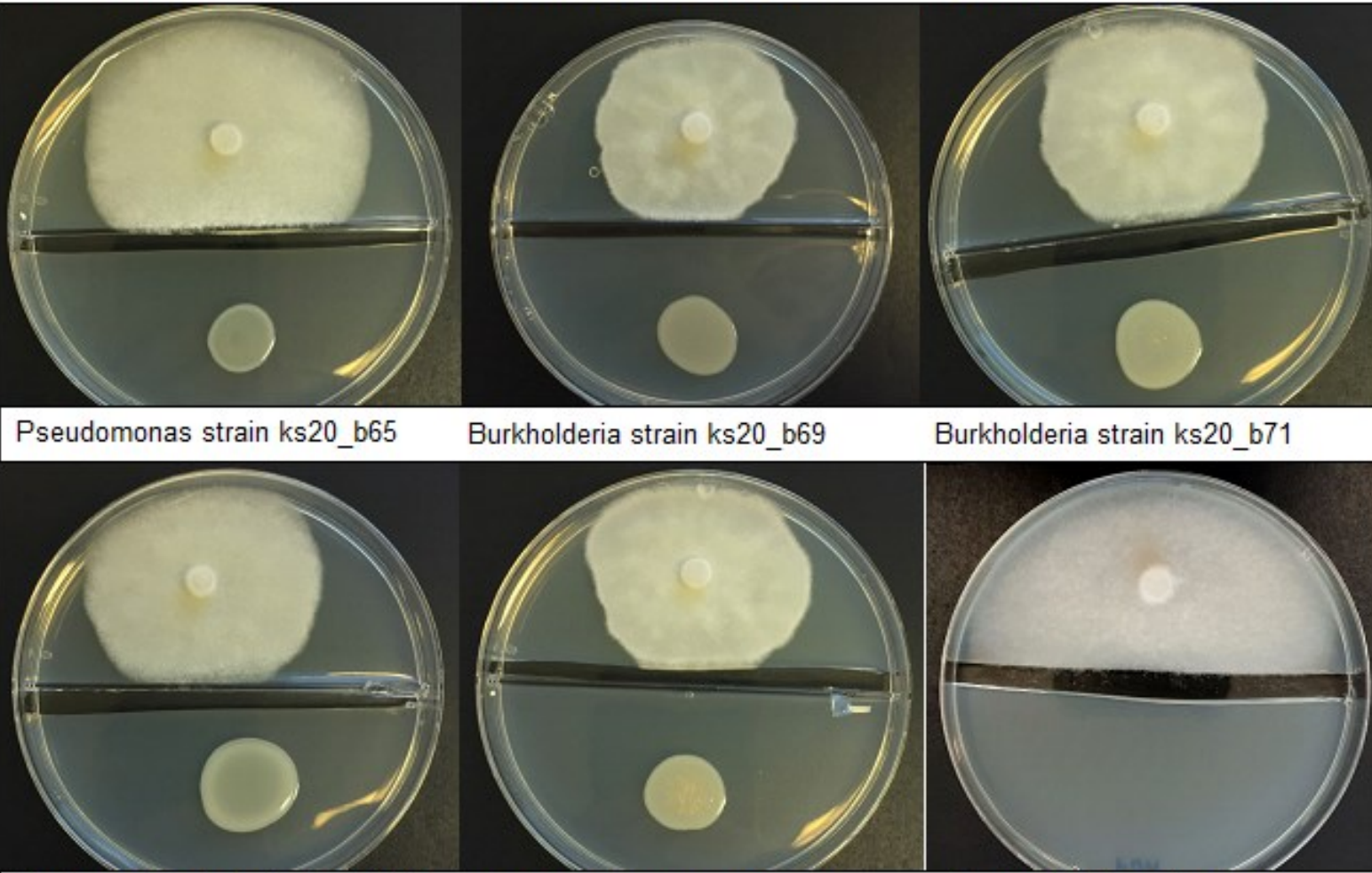

Burkholderia strain ks20_b69

Burkholderia strain ks20_b71
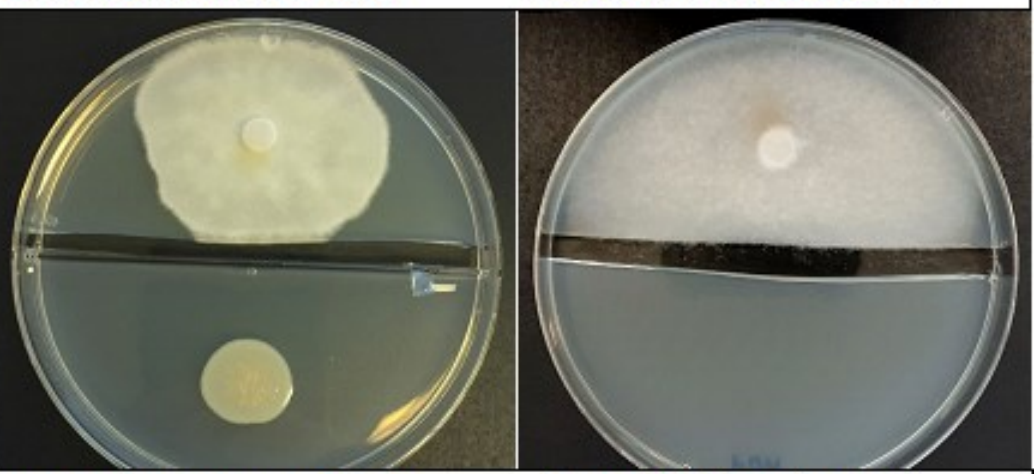

Paraburkholderia strain ks20_b72

Burkholderia strain ks20_b74

P. agathidicida only control

Figure S2 Example images of the bacterial split plate bioassays used to assess whether the microbial isolates may be producing VOCs which are inhibiting the mycelial growth of Phytophthora agathidicida. 


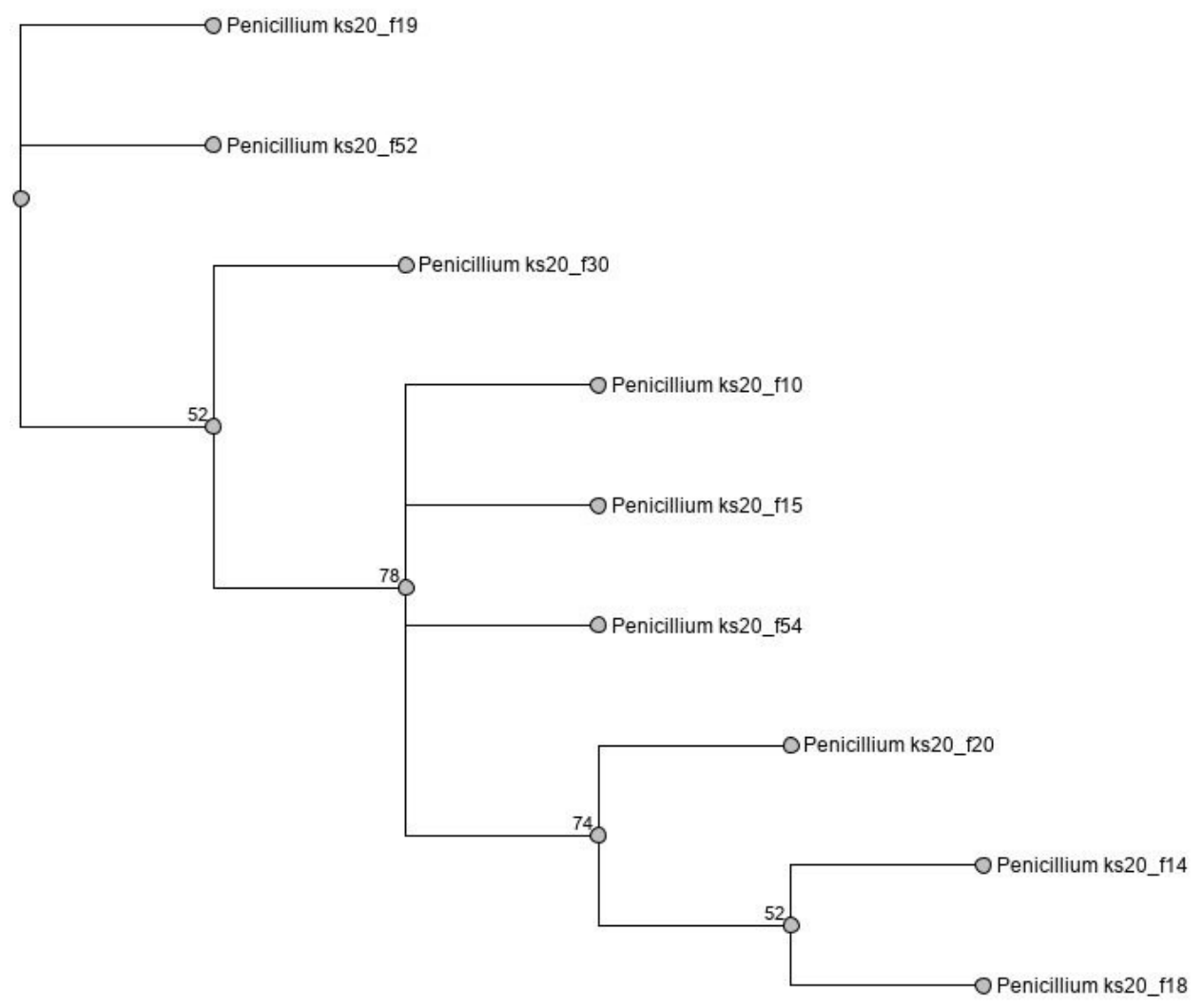

Figure S3 The phylogenetic relationships of the Penicillium strains isolated in this study, based on the alignment of their ITS2 gene region sequences. The phylogenetic tree was constructed using the Neighbour Joining tree build method with Tamura Nei selected as the genetic distance model and resampling performed using bootstrapping. Bootstrap values are shown as percentages next to the branches.

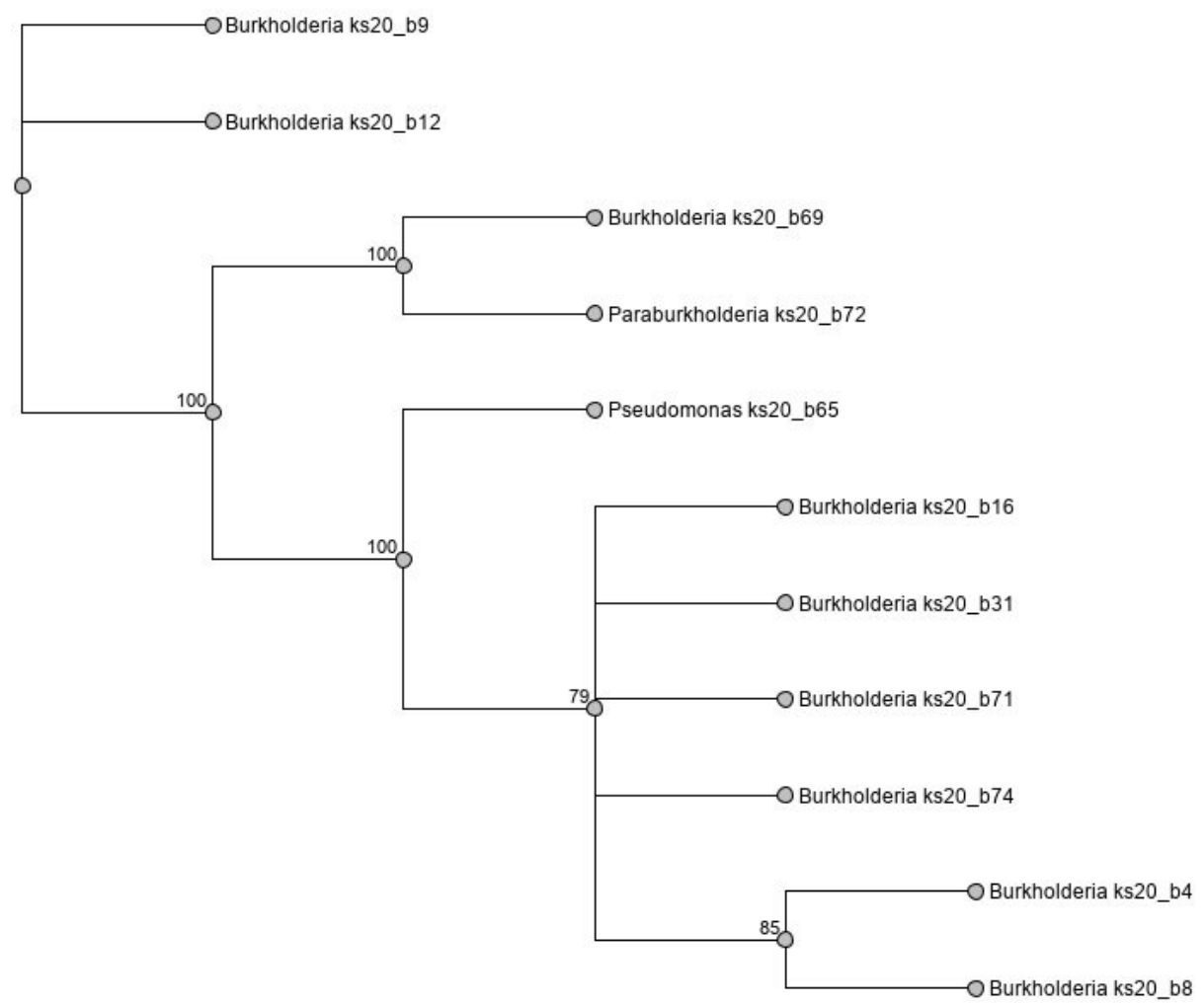

Figure S4 The phylogenetic relationships of the bacterial strains identified to inhibit P. agathidicida, based on the alignment of their 16S rRNA gene region sequences. Phylogenetic tree was constructed using the Neighbour Joining tree build method with Tamura Nei selected as the genetic distance model and resampling performed using bootstrapping. Bootstrap values are shown as percentages next to the branches. 

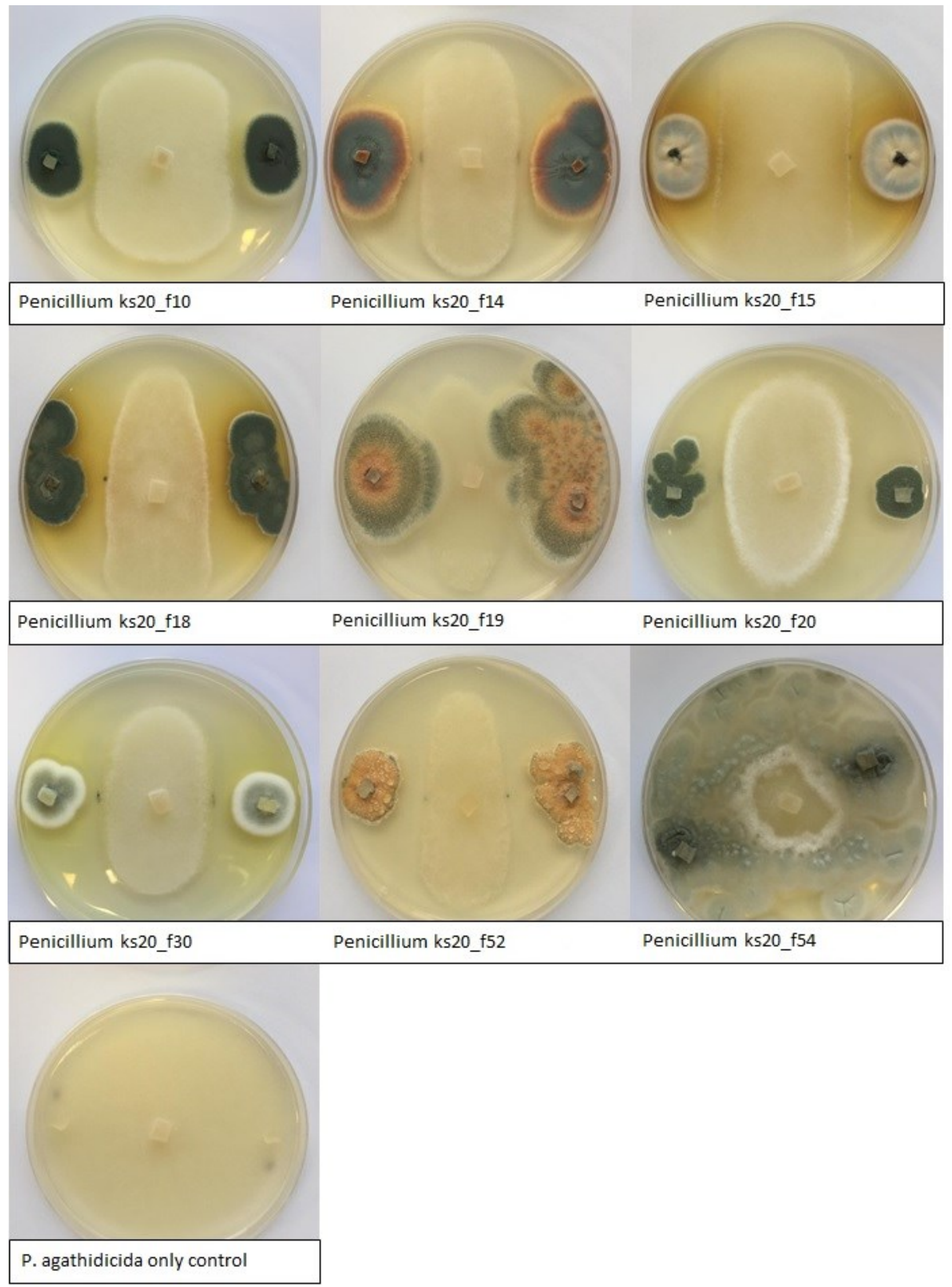

Figure S5 The fungal isolates that significantly reduced $P$. agathidicida mycelial growth compared with $P$. agathidicida only controls in dual culture bioassays. 


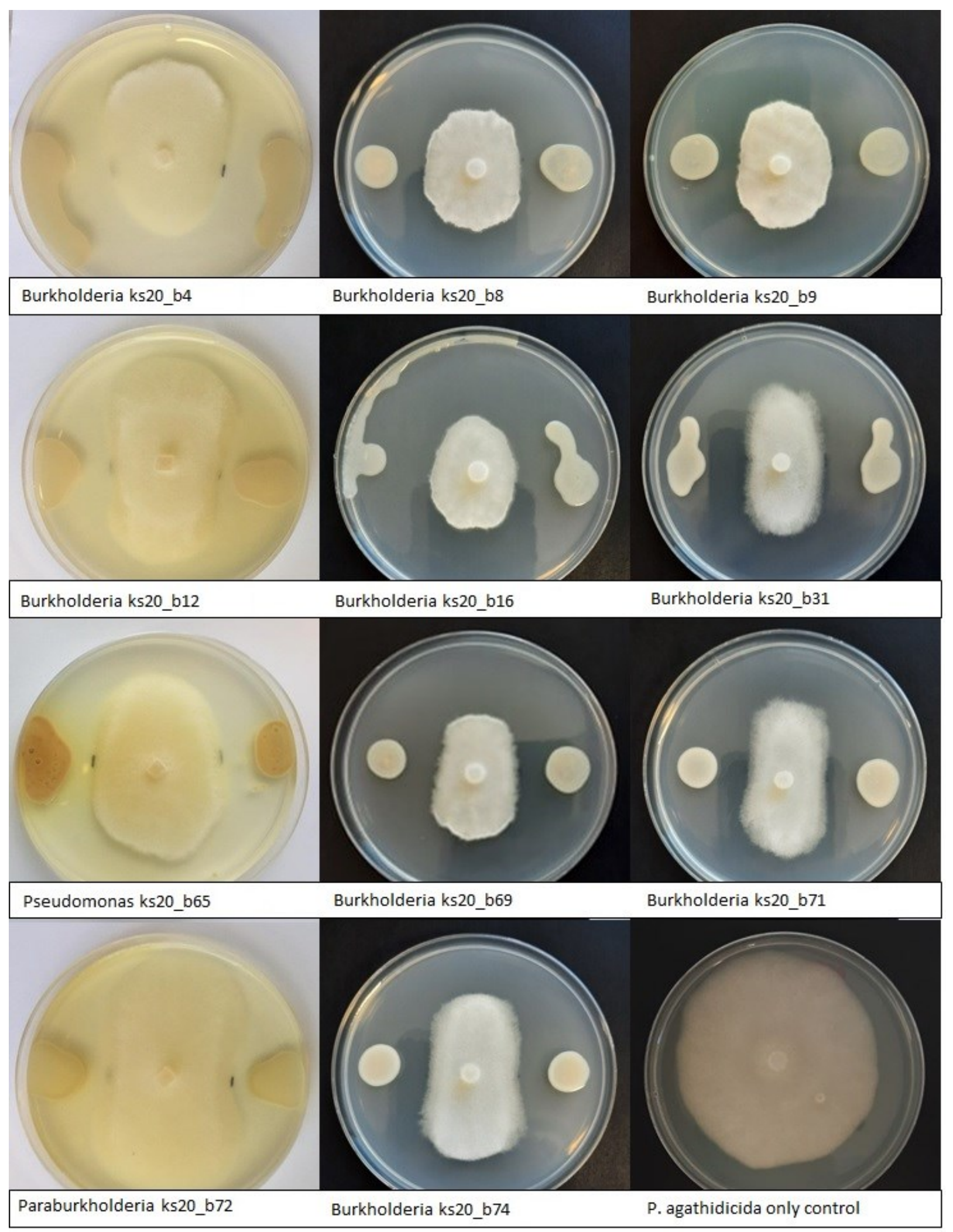

Figure S6 The bacterial isolates that significantly reduced P. agathidicida mycelial growth compared with P. agathidicida only controls in dual culture bioassays. 


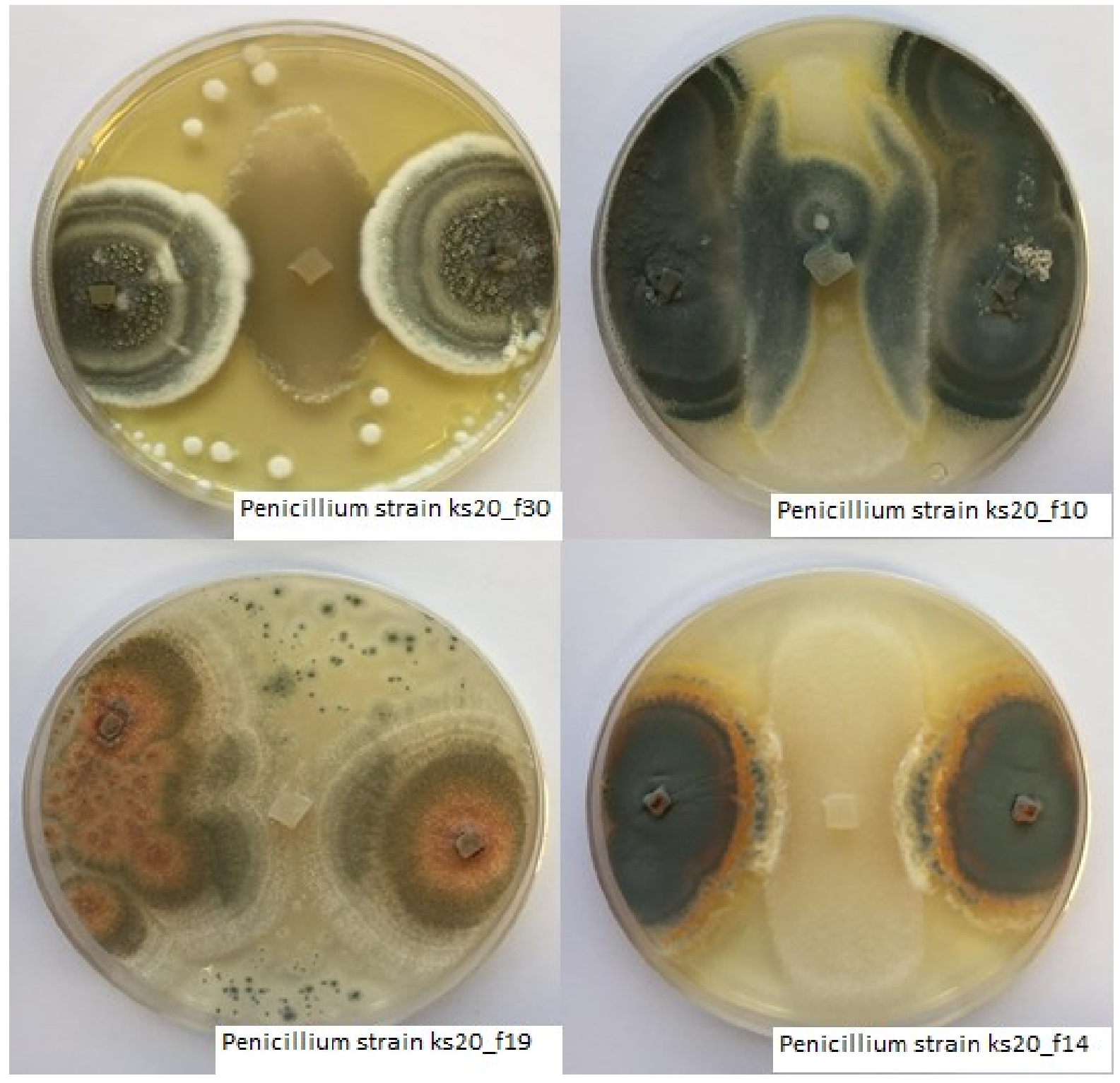

Figure S7 Fungal isolates which grew over P. agathidicida mycelium when screened using dual culture bioassays. 


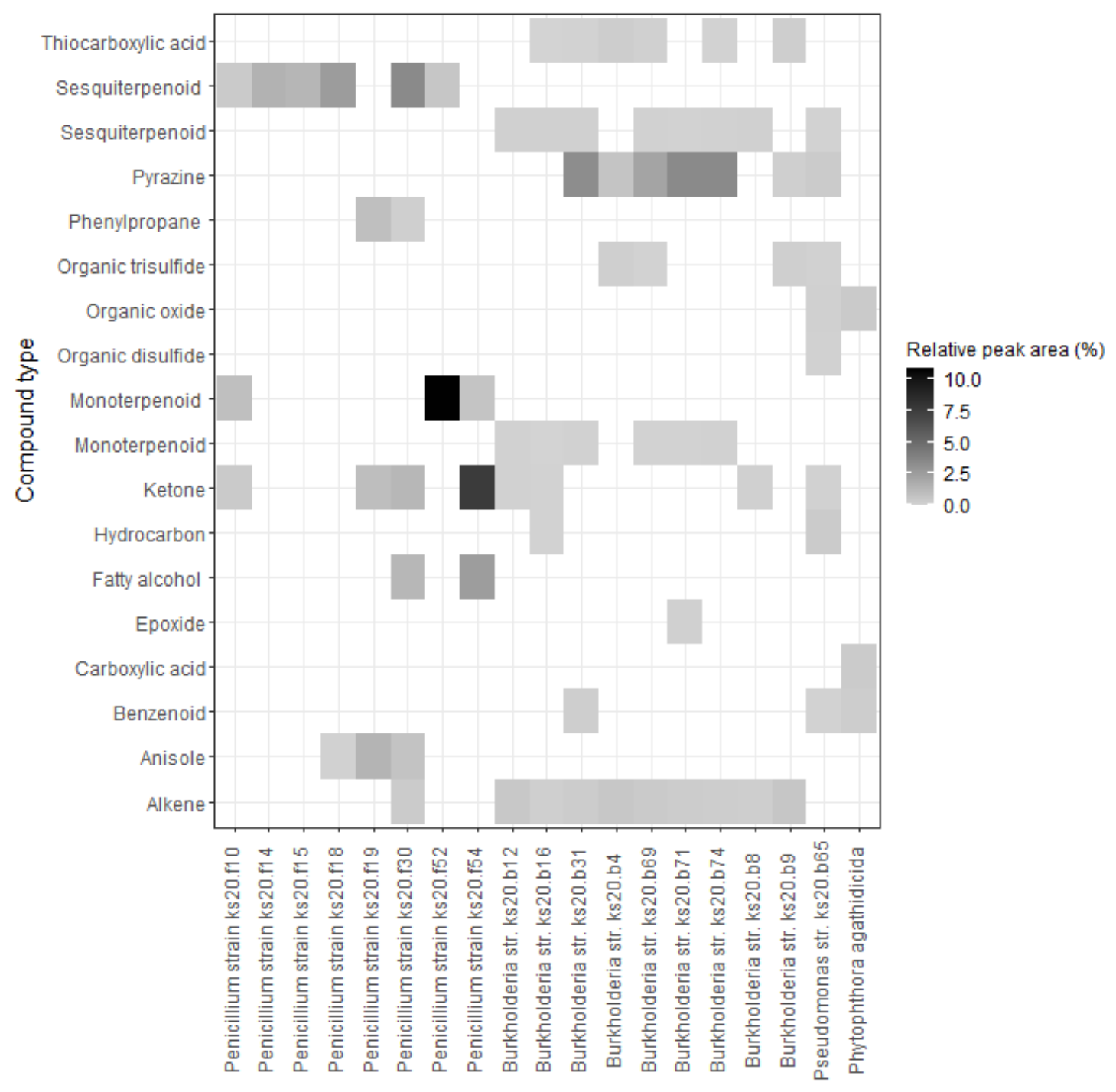

Figure S8 The peak areas (\%) of the putatively identified chemical classes detected as being released by fungal isolates, bacterial isolates, and Phytophthora agathidicida relative to the total peak area for all compounds using HS SPME-GC-MS analysis. For all samples, siloxane contaminants from the vials constituted most of the VOCs detected in the headspace (not shown). 


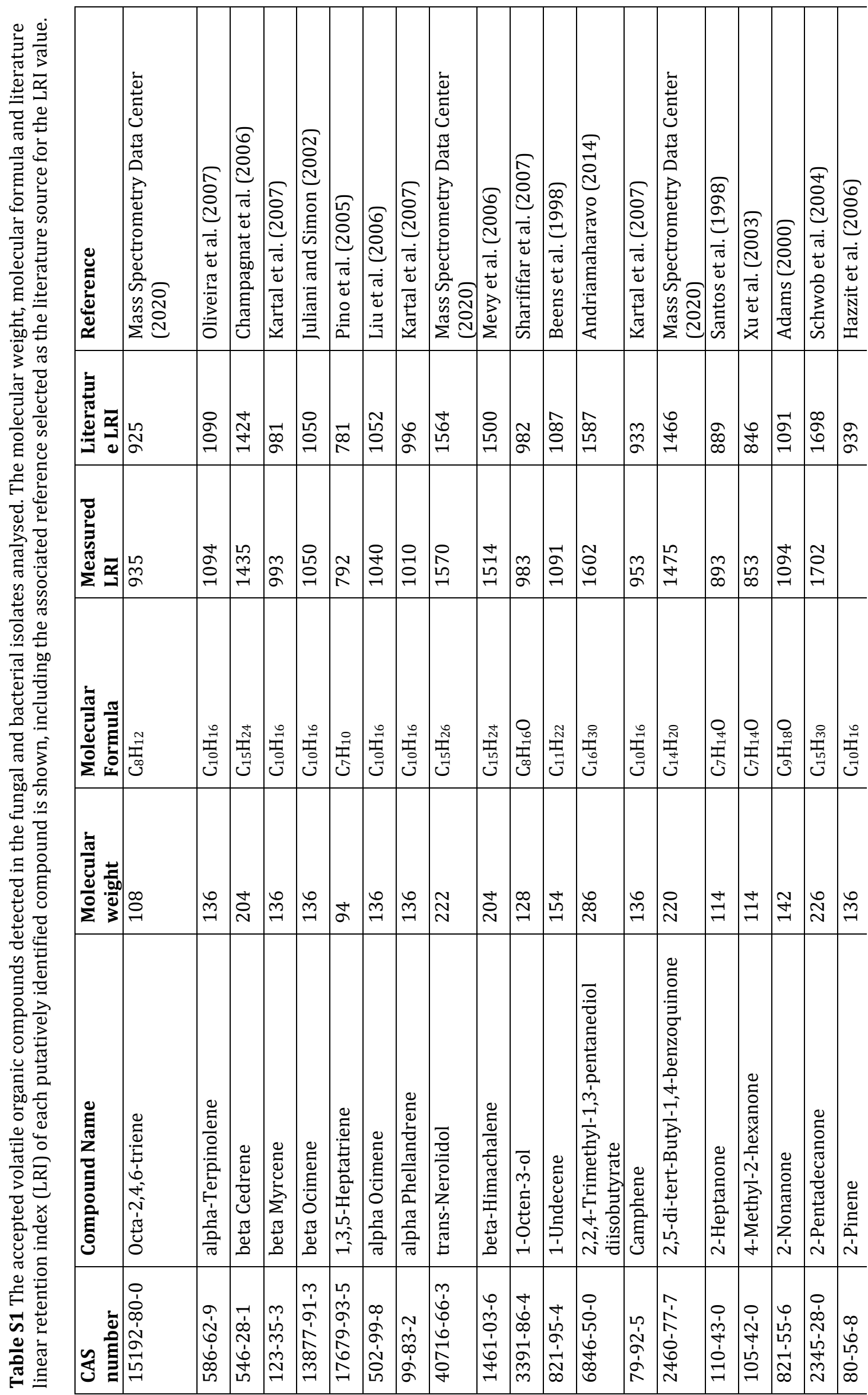




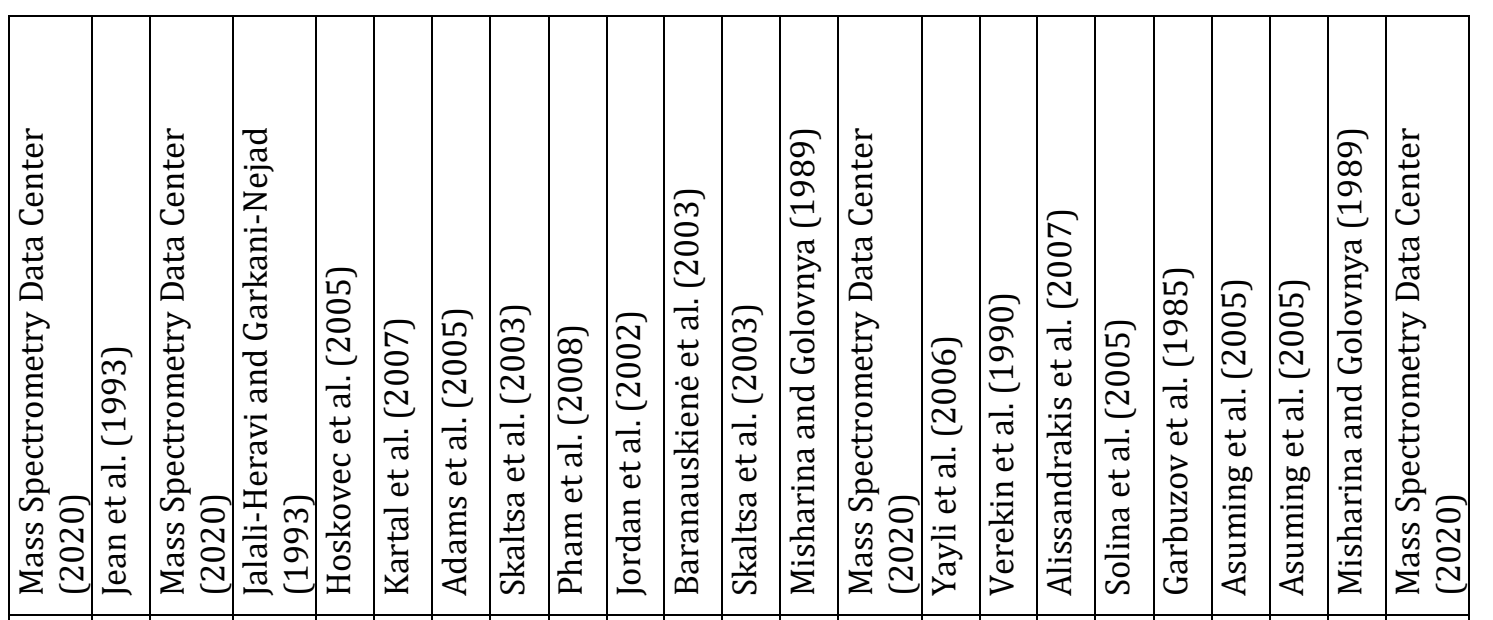

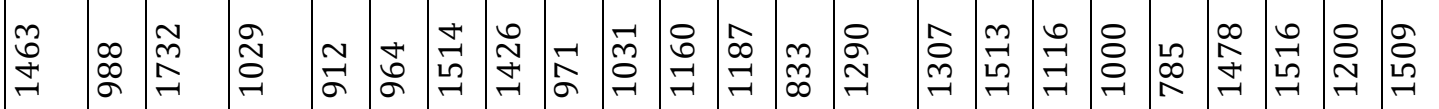

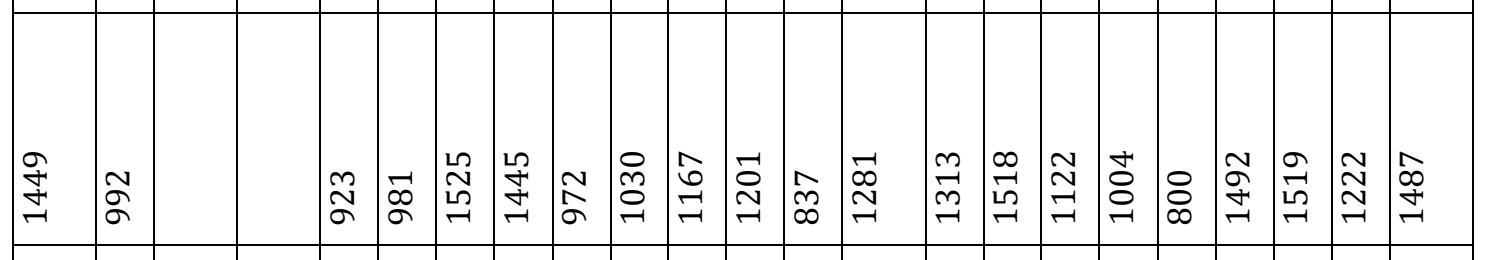

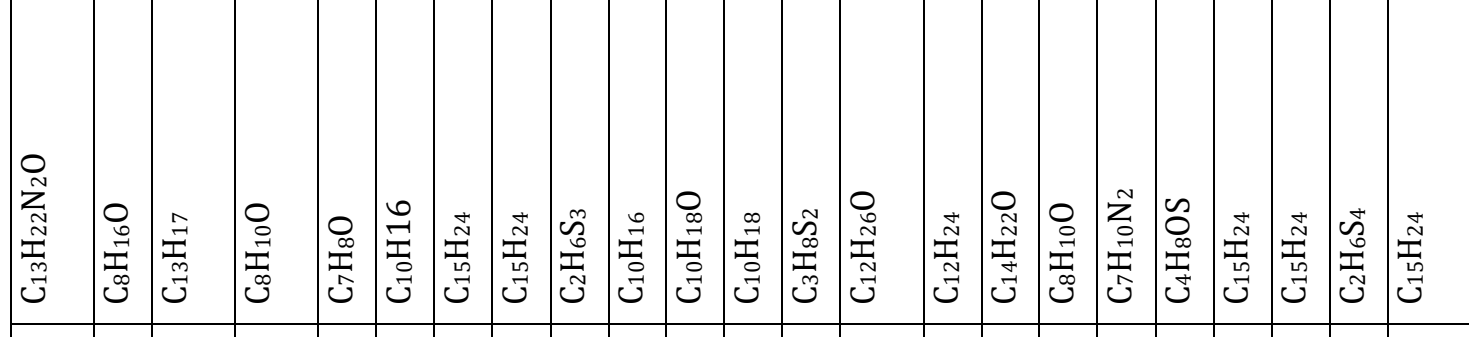

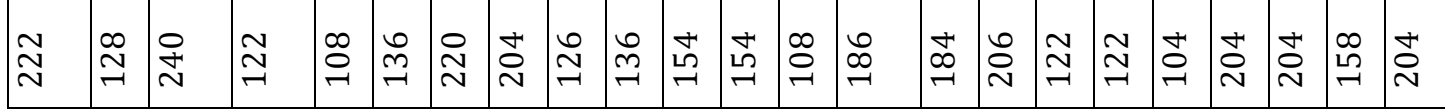

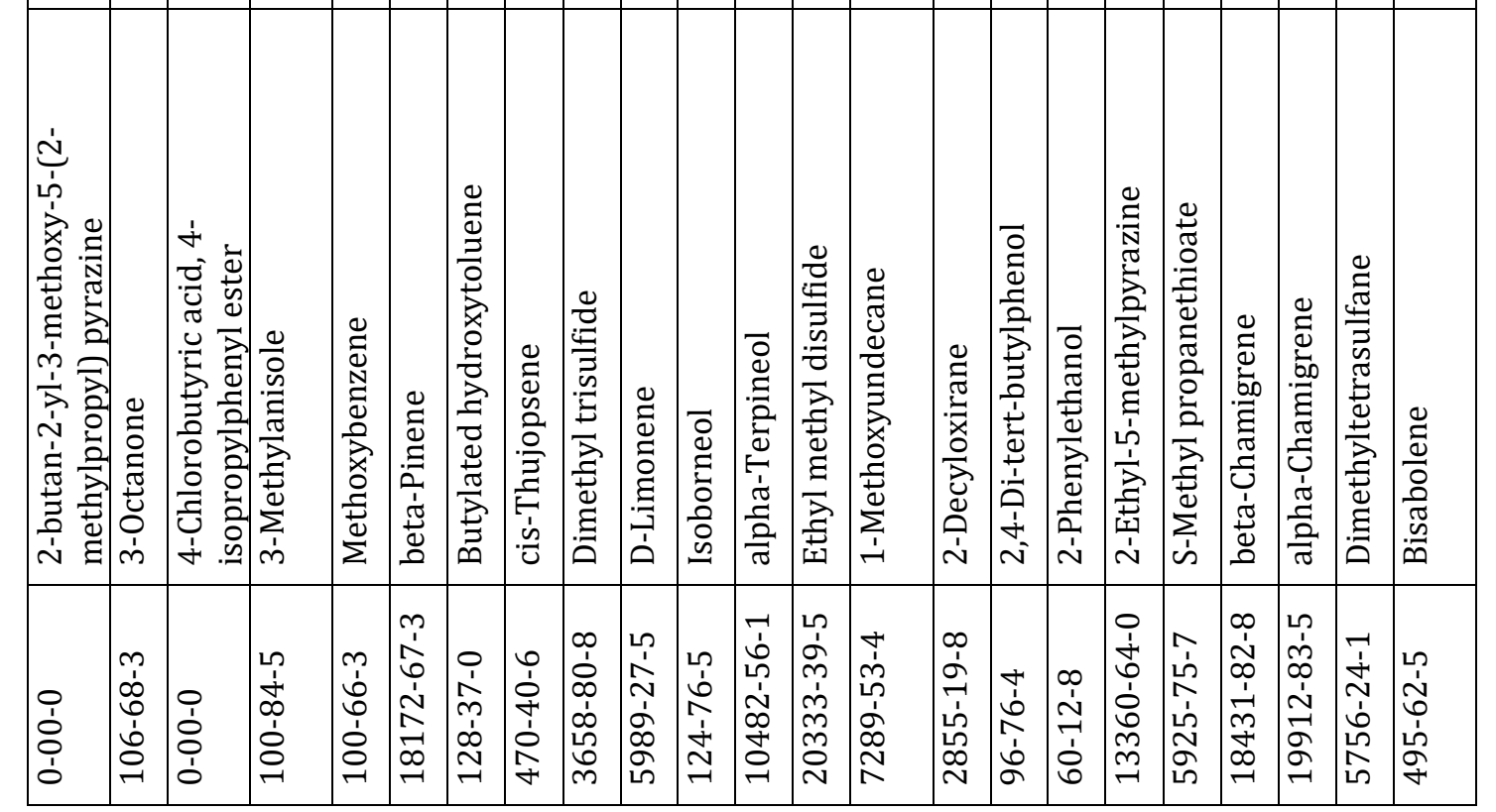




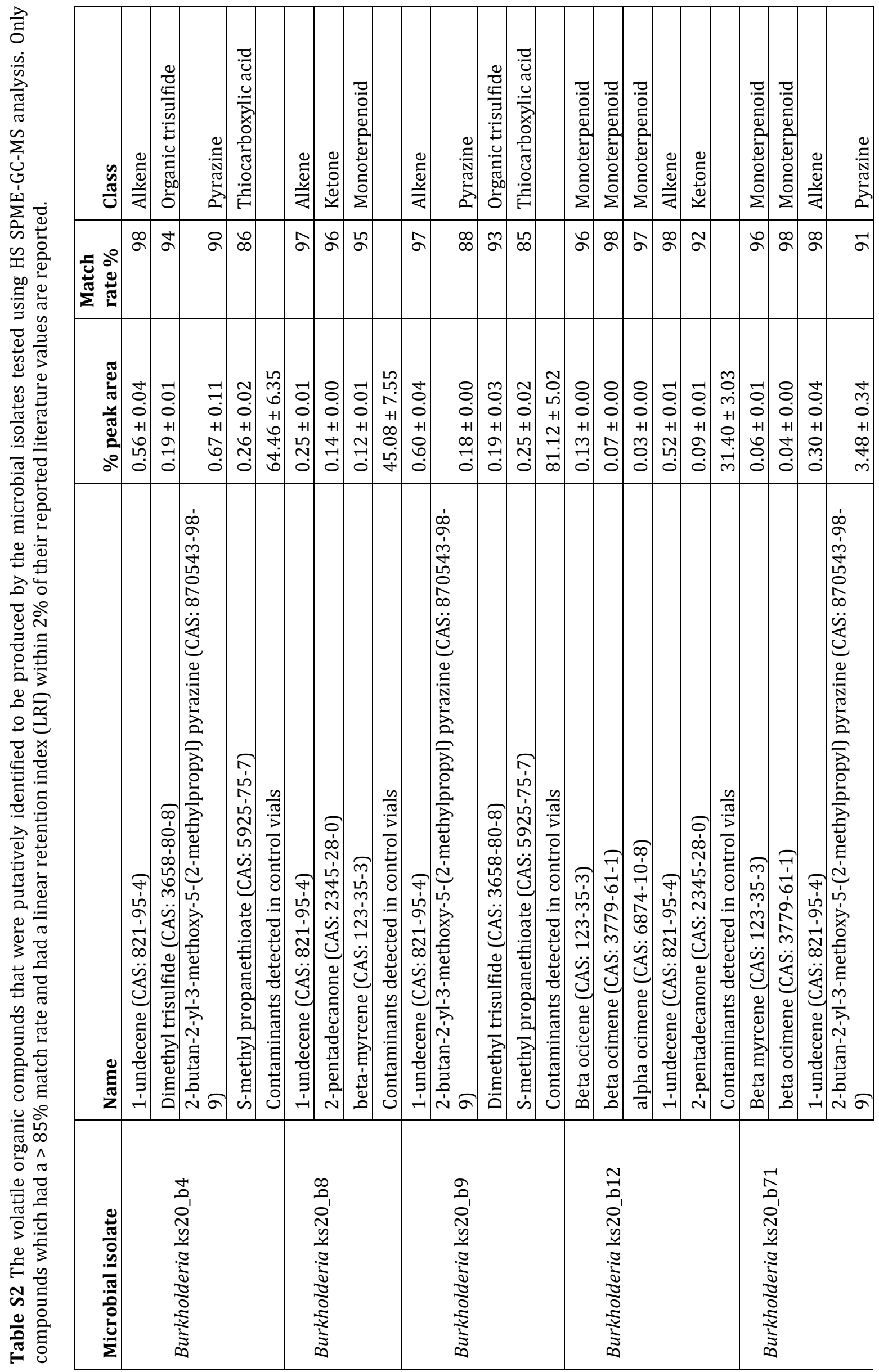




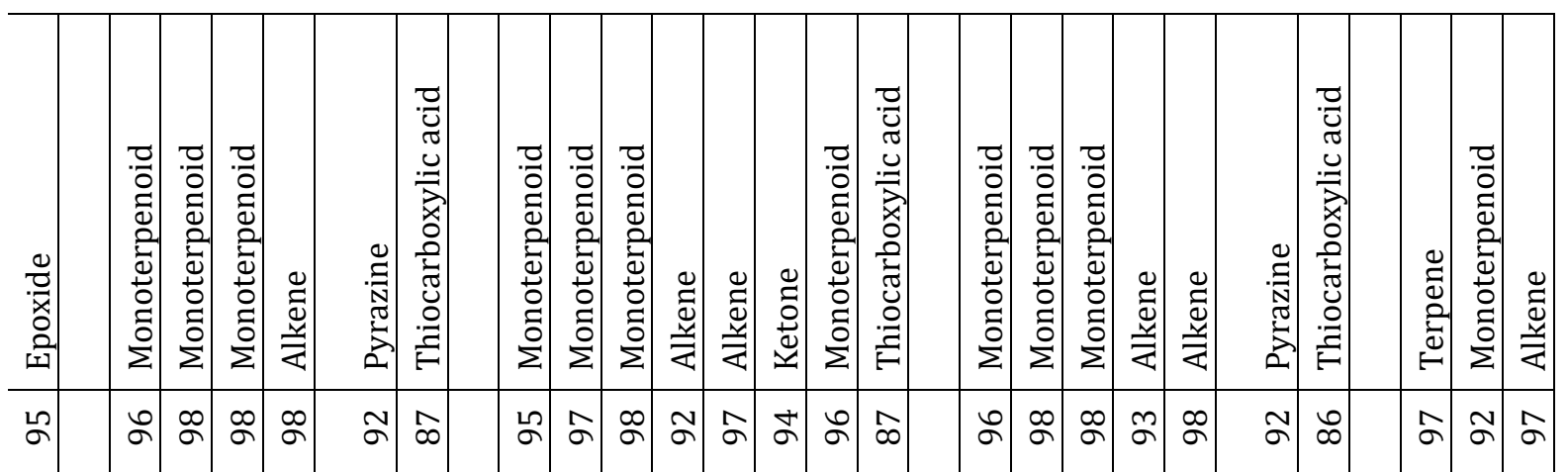

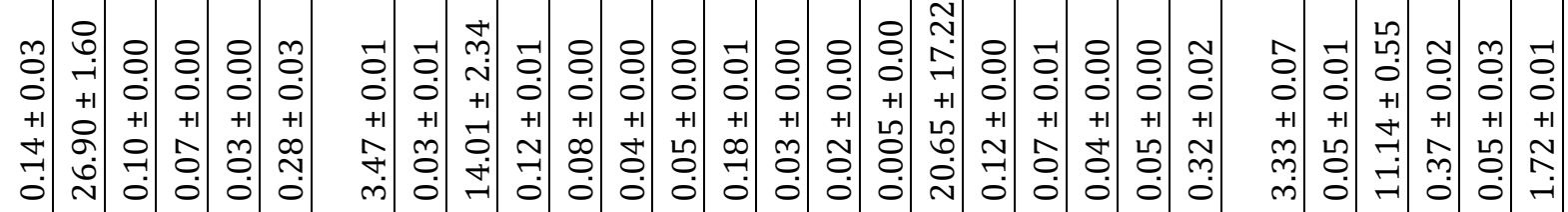

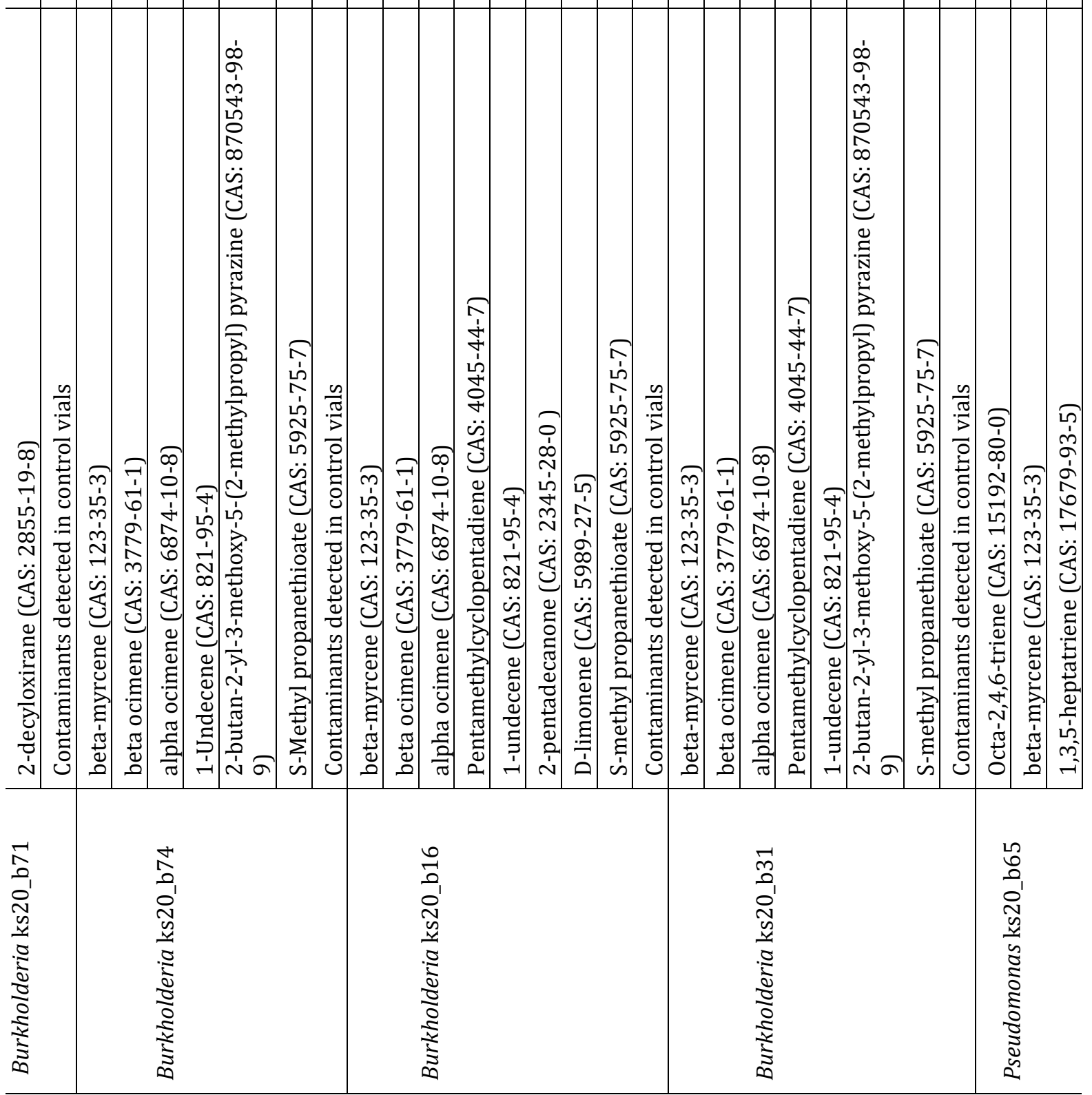




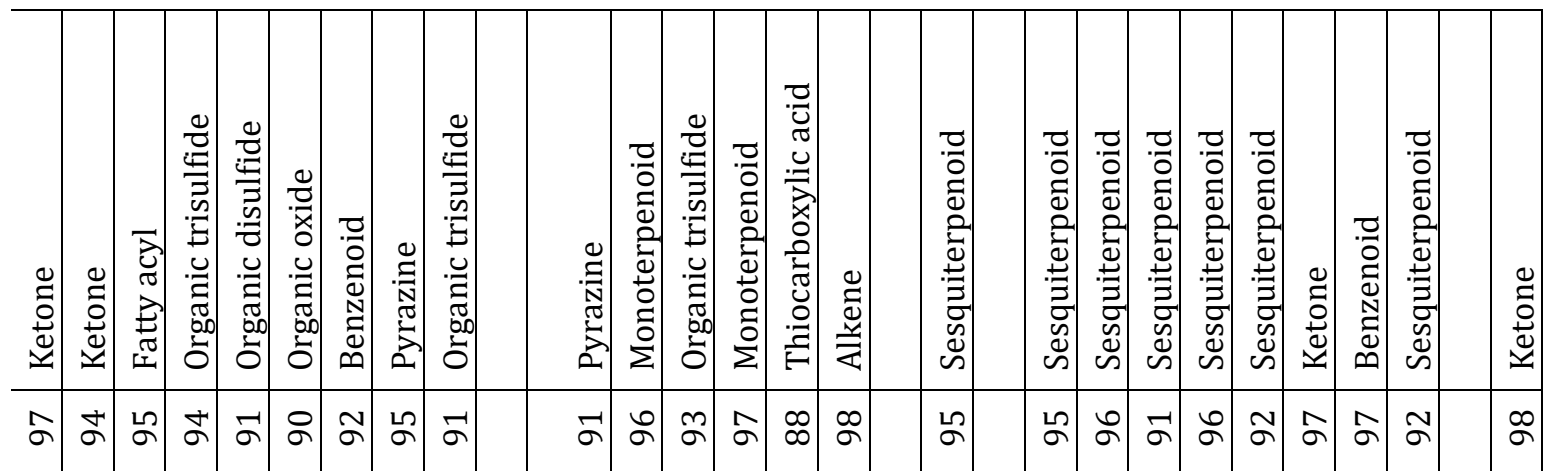

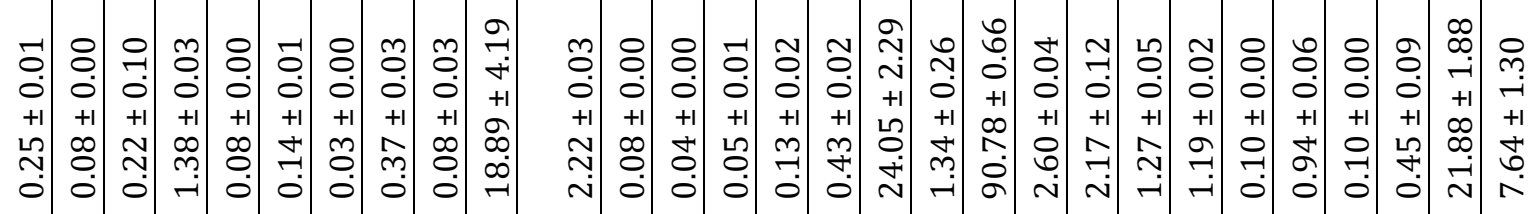

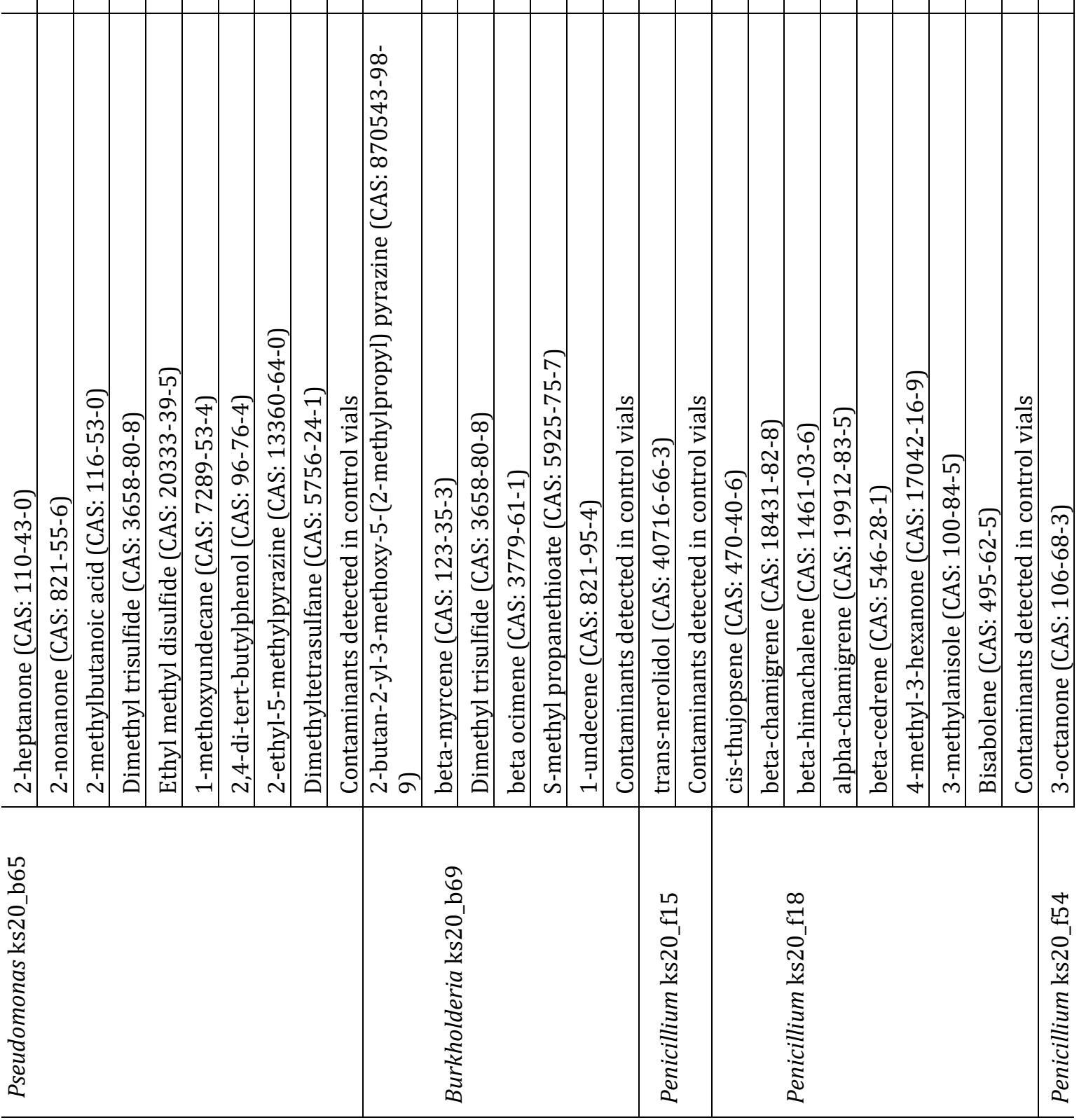




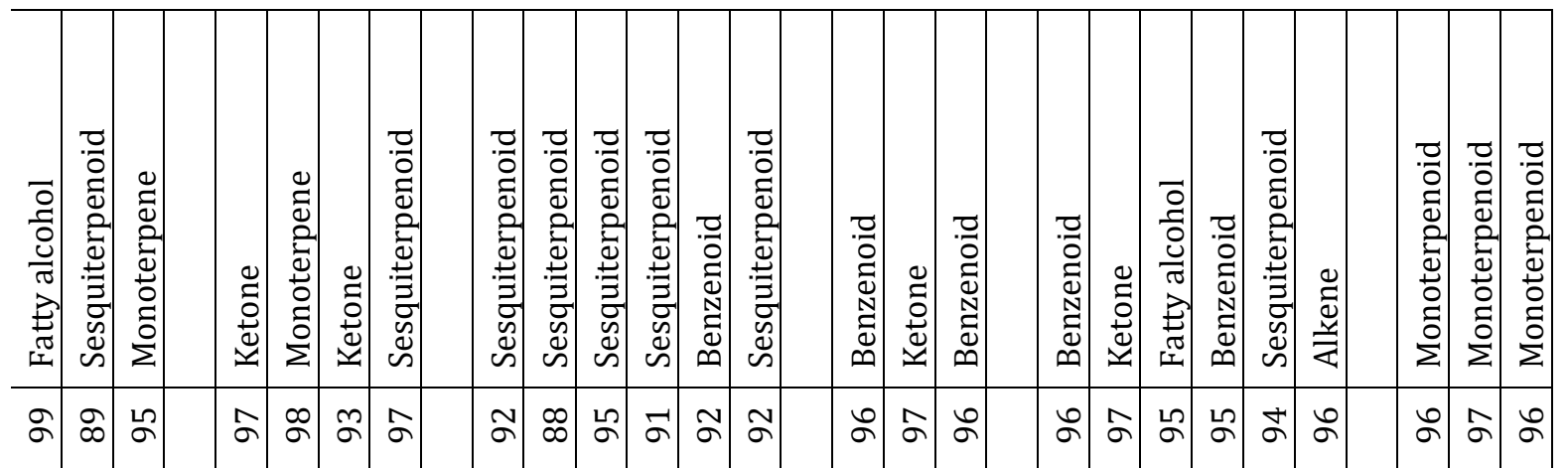

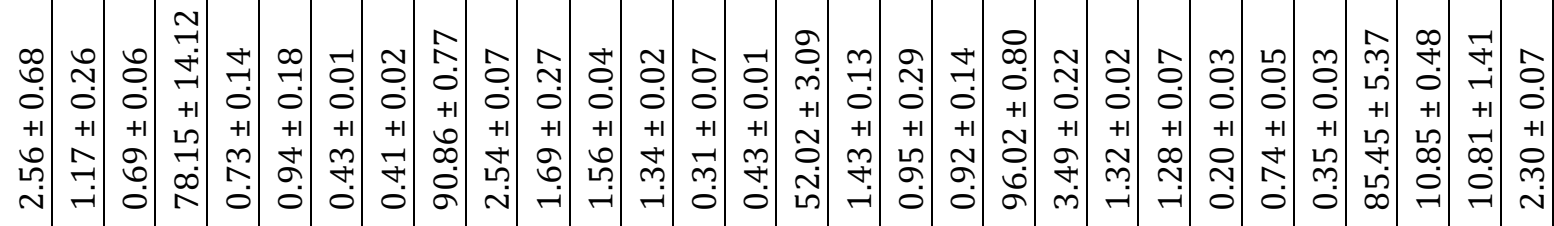

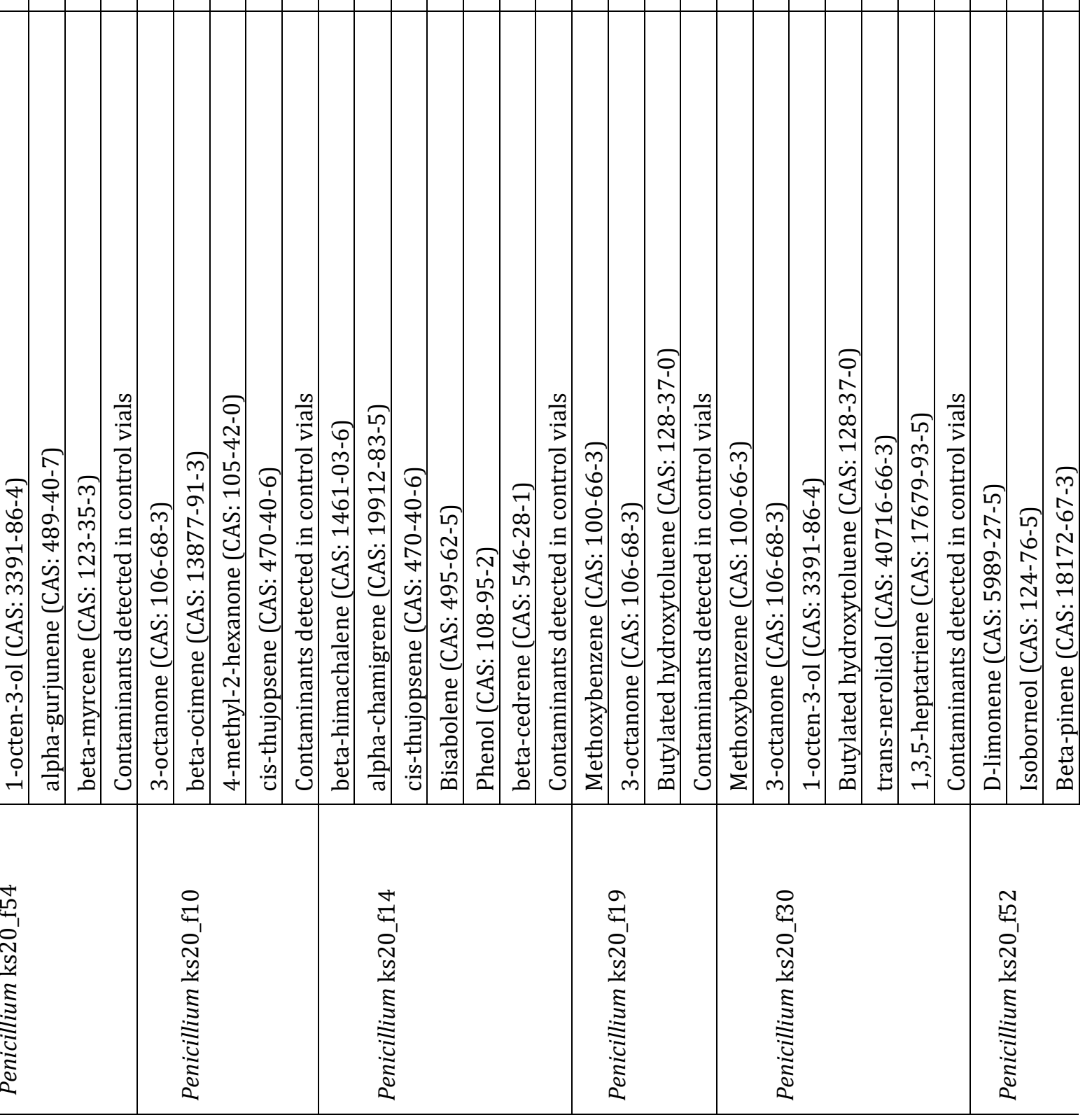




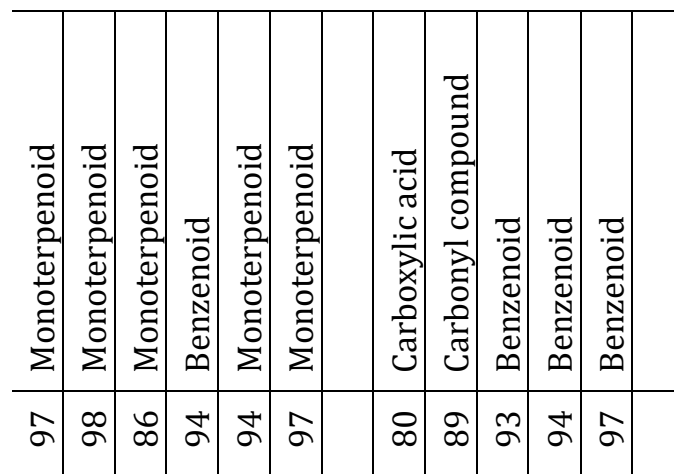

영명

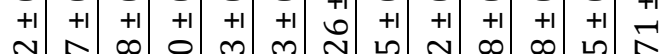

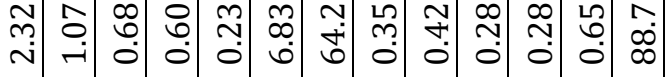

จ

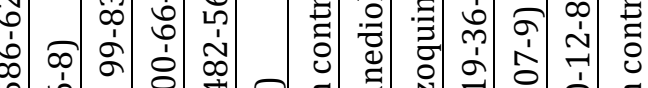

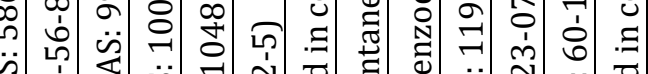

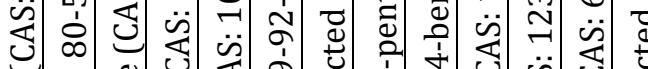
¿

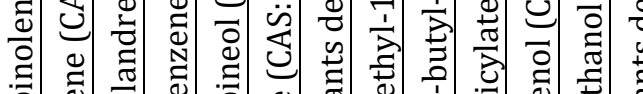

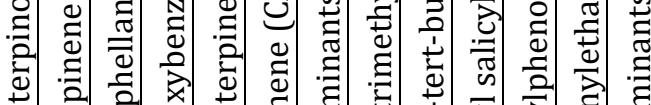

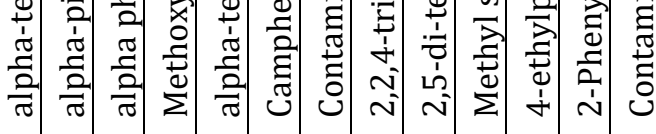

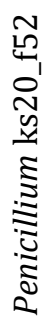

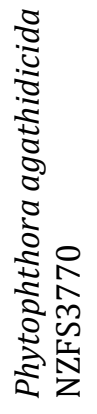




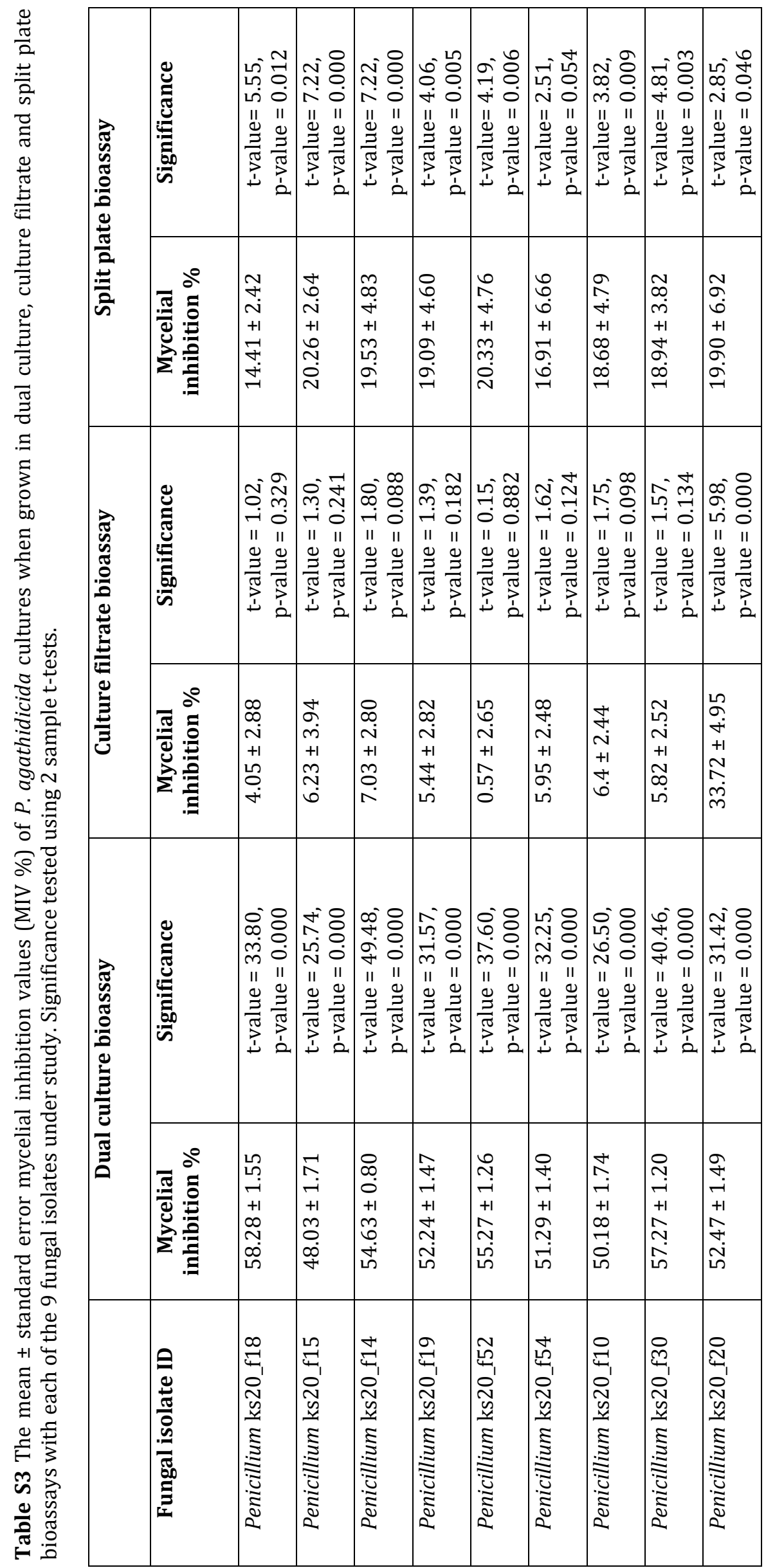




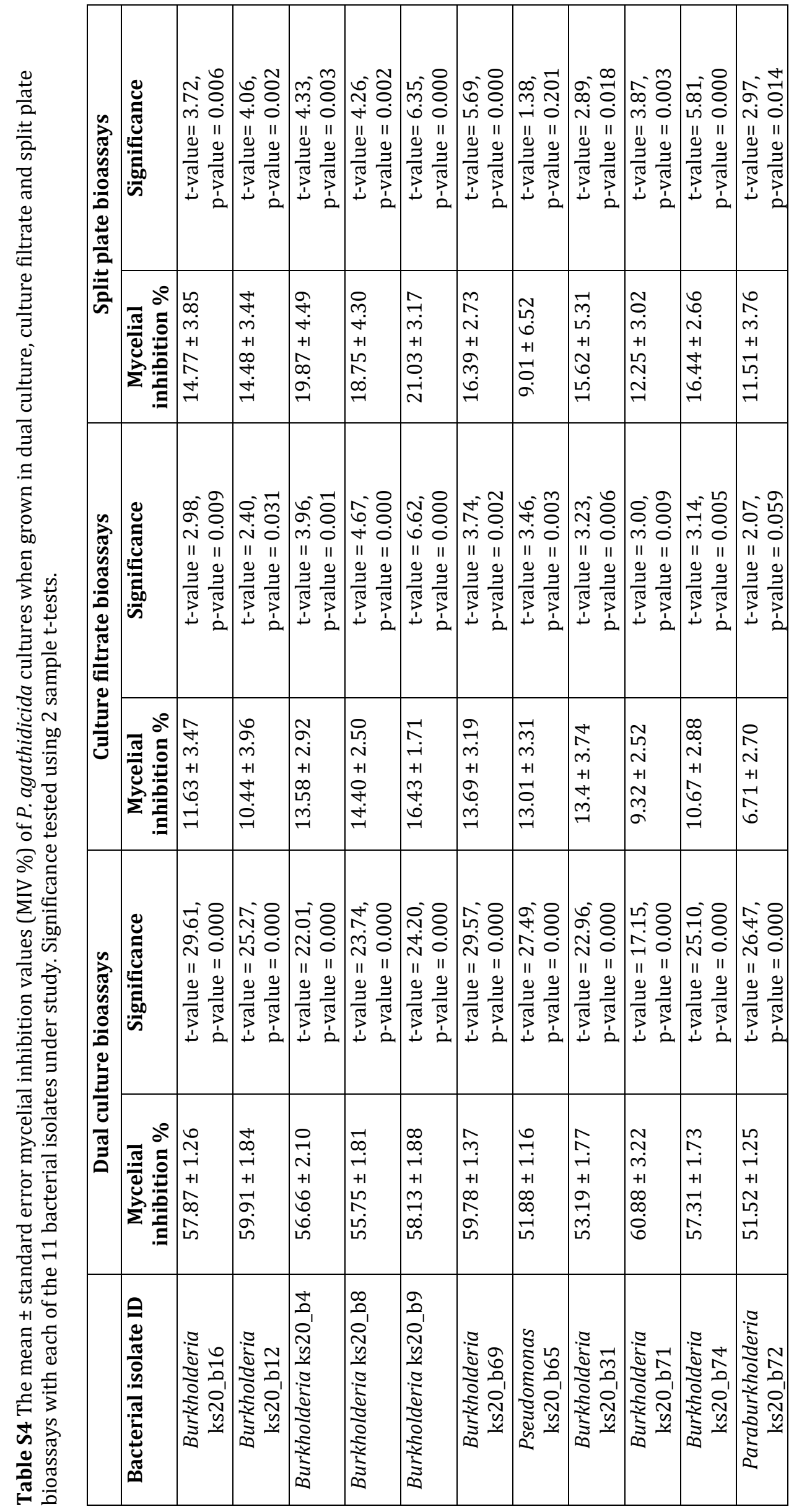




\section{References: Supplementary Materials}

Adams RP 2000. Systematics of the one seeded Juniperus of the eastern hemisphere based on leaf essential oils and random amplified polymorphic DNAs (RAPDs). Biochemical Systematics and Ecology 28: 529-543. https://doi.org/10.1016/S0305-1978(99)00096-4

Adams RP, Morris JA, Pandey RN, Schwarzbach AE 2005. Cryptic speciation between Juniperus deltoides and Juniperus oxycedrus (Cupressaceae) in the Mediterranean. Biochemical Systematics and Ecology 33: 771-787. https://doi.org/10.1016/j.bse.2005.01.001

Alissandrakis E, Tarantilis PA, Harizanis PC, Polissiou M 2007. Comparison of the volatile composition in thyme honeys from several origins in Greece. Journal of Agricultural and Food Chemistry 55: 8152-8157. https://doi.org/10.1021/if071442y

Andriamaharavo NR 2014. Retention Data. NIST Mass Spectrometry Data Center.

Asuming WA, Beauchamp PS, Descalzo JT, Dev BC, Dev V, Frost S, Ma CW 2005. Essential oil composition of four Lomatium Raf. species and their chemotaxonomy. Biochemical Systematics and Ecology 33: 17-26. https://doi.org/10.1016/j.bse.2004.06.005

Baranauskienė R, Venskutonis PR, Viškelis P, Dambrauskienė E 2003. Influence of nitrogen fertilizers on the yield and composition of thyme (Thymus vulgaris). Journal of Agricultural and Food Chemistry 51: 7751-7758. https://doi.org/10.1021/if0303316

Beens J, Tijssen R, Blomberg J 1998. Prediction of comprehensive two-dimensional gas chromatographic separations: A theoretical and practical exercise. Journal of Chromatography A 822: 233-251. https://doi.org/10.1016/S00219673(98)00649-9

Champagnat P, Figueredo G, Chalchat JC, Bessière JM 2006. Essential oil composition of Vetiveria nigritana from Mali. Journal of Essential Oil Research 18: 647-649. https://doi.org/10.1080/10412905.2006.9699193

Garbuzov VG, Misharina TA, Aerov AF, Golovnya RV 1985. Gas chromatographic retention indices for sulphur (II)containing organic substances. The Journal of Analytical Chemistry USSR 40: 76-586.

Hazzit M, Baaliouamer A, Faleiro ML, Miguel MG 2006. Composition of the essential oils of Thymus and Origanum species from Algeria and their antioxidant and antimicrobial activities. Journal of Agricultural and Food Chemistry 54: 63146321. https://doi.org/10.1021/jf0606104

Hoskovec M, Grygarová D, Cvačka J, Streinz L, Zima J, Verevkin SP, Koutek B 2005. Determining the vapour pressures of plant volatiles from gas chromatographic retention data. Journal of Chromatography A 1083: 161-172. https://doi.org/10.1016/j.chroma.2005.06.006

Jalali-Heravi M, Garkani-Nejad Z 1993. Prediction of gas chromatographic retention indices of some benzene derivatives. Journal of Chromatography A 648: 389-393. https://doi.org/10.1016/0021-9673(93)80421-4

Jean FI, Garneau FX, Collin GJ, Bouhajib M, Zamir LO 1993. The essential oil and glycosidically bound volatile compounds of Taxus canadensis Marsh. Journal of Essential Oil Research 5: 7-11. https://doi.org/10.1080/10412905.1993.9698163

Jordan MJ, Margaria CA, Shaw PE, Goodner KL 2002. Aroma active components in aqueous kiwi fruit essence and kiwi fruit puree by GC-MS and multidimensional GC/GC-0. Journal of Agricultural and Food Chemistry 50: 5386-5390. https://doi.org/10.1021/jf020297f

Juliani HR, Simon JE 2002. Antioxidant activity of basil. In: Janick J, Whipkey A eds. Trends in New Crops and New Uses. ASHS Press, Alexandria, VA. Pp 575-579.

Kartal N, Sokmen M, Tepe B, Daferera D, Polissiou M, Sokmen A 2007. Investigation of the antioxidant properties of Ferula orientalis L. using a suitable extraction procedure. Food Chemistry 100: 584-589. https://doi.org/10.1016/j.foodchem.2005.09.084

Liu J, Nan P, Tsering Q, Tsering T, Bai Z, Wang L, Liu Z, Zhong Y 2006. Volatile constituents of the leaves and flowers of Salvia przewalskii Maxim. from Tibet. Flavour and Fragrance Journal 21: 435-438. https://doi.org/10.1002/ffj.1607

Mass Spectrometry Data Center (2020) Retrieved from https://www.nist.gov/srd/nist-standard-reference-database-1a

Mevy JP, Bousquet-Mélou A, Greff S, Millogo J, Fernandez C 2006. Chemical composition of the volatile oil of Laggera aurita Schulz from Burkina-Faso. Biochemical Systematics and Ecology 34: 815-818. https://doi.org/10.1016/j.bse.2006.06.005

Misharina T, Golovnya R 1989. Regularities of retention of a pseudohomologous series of dialkylpolysulfides in capillary gas chromatography. Zhurnal Analiticheskoi Khimii 44: 514-519.

Oliveira DR, Leitao GG, Bizzo HR, Alviano DS, Alviano CS, Leitão SG 2007. Chemical and antimicrobial analyses of essential oil of Lippia origanoides HBK. Food Chemistry 101: 236-240. https://doi.org/10.1016/j.foodchem.2006.01.022

Pham AJ, Schilling MW, Yoon Y, Kamadia VV, Marshall DL 2008. Characterization of fish sauce aroma-impact compounds using GC-MS, SPME-osme-GCO, and Stevens' power law exponents. Journal of Food Science 74: C268-C274. https://doi.org/10.1111/j.1750-3841.2008.00709.x

Pino JA, Mesa J, Muñoz Y, Martí MP, Marbot R 2005. Volatile components from mango (Mangifera indica L.) cultivars. Journal of Agricultural and Food Chemistry 53: 2213-2223. https://doi.org/10.1021/jf0402633

Santos AS, Andrade EHDA, Zoghbi MDGB, Maia JGS 1998. Volatile constituents of fruits of Annona glabra L. from Brazil. Flavour and Fragrance Journal 13: 148-150. https://doi.org/10.1002/(SICI)1099-1026(199805/06)13:3<148::AID$\underline{\mathrm{FF}] 711>3.0 . \mathrm{CO} 0 ; 2-\mathrm{Y}}$ 
Schwob I, Bessiere JM, Masotti V, Viano J 2004. Changes in essential oil composition in Saint John's wort (Hypericum perforatum L.) aerial parts during its phenological cycle. Biochemical Systematics and Ecology 32: 735-745. https://doi.org/10.1016/i.bse.2003.12.005

Sharififar F, Mozaffarian V, Moradkhani S 2007. Comparison of antioxidant and free radical scavenging activities of the essential oils from flowers and fruits of Otostegia persica Boiss. Pakistan Journal of Biological Sciences 10: 3895-3899. https://doi.org/10.3923/pjbs.2007.3895.3899

Skaltsa HD, Demetzos C, Lazari D, Sokovic M 2003. Essential oil analysis and antimicrobial activity of eight Stachys species from Greece. Phytochemistry 64: 743-752. https://doi.org/10.1016/S0031-9422(03)00386-8

Solina M, Baumgartner P, Johnson RL, Whitfield FB 2005. Volatile aroma components of soy protein isolate and acidhydrolysed vegetable protein. Food Chemistry 90: 861-873. https://doi.org/10.1016/i.foodchem.2004.06.005

Verekin SP, Nesterov OA, Rempel PD, Synkova NV, Shashkin NP 1990. Chromatographic determination of the products of condensation of alkylphenols with formic aldehyde. Zhurnal Analiticheskoi Khimii 43: 760-761.

Xu X, Stee LLP, Williams J, Beens J, Adahchour M, Vreuls RJJ, Brinkman UA, Lelieveld J 2003. Comprehensive twodimensional gas chromatography (GC $\times$ GC) measurements of volatile organic compounds in the atmosphere. Atmospheric Chemistry and Physics 3: 665-682. https://doi.org/10.5194/acp-3-665-2003

Yayli N, Gülec C, Üçüncü O, Yaşar A, Ülker S, Coşkunçelebi K, Terzioğlu S 2006. Composition and antimicrobial activities of volatile components of Minuartia meyeri. Turkish Journal of Chemistry 30: 71-76. 